Article

\title{
Tender Management Relating to Imposition of Public Service Obligations on Scheduled Air Routes: An Approach Involving Digital Transformation of Procurement Procedures in Spain
}

\author{
Antonio Martínez Raya * (1) and Víctor M. González-Sánchez \\ Department of Applied Economics, Faculty of Economic and Business Sciences, UNED—National University of \\ Distance Education, 28040 Madrid, Spain; vgonzalez@cee.uned.es \\ * Correspondence: amartinez@cee.uned.es; Tel.: +34-91-3987829
}

Received: 31 May 2020; Accepted: 25 June 2020; Published: 1 July 2020

check for updates

\begin{abstract}
The promotion of efficient and sustainable means of transport has been a key issue of public debate across the European Union (EU). Particularly, transport needs in peripheral and remote areas have a great importance for EU transport policies in order to ensure the mobility of goods and persons in these regions, and thus to achieve greater territorial cohesion in the member states concerned. Despite the remarkable efforts to improve the competitiveness of aviation in the EU single market, certain regional routes have traditionally suffered a lack of scheduled air routes. The internal market, once liberalized, has provided an instrument in order to ensure adequate transportation for the carriage of goods and persons in special cases. When this occurs, according to Regulation (CE) no. 1008/2008, national civil aviation authorities may impose a public service obligation (PSO) on specific air routes. In addition, this form of public intervention can lead to restriction on market access to one carrier, and even to the payment of compensation to the awarded airline through the launching of a tendering procedure for the operation of the required air service. In the case of Spain, this type of administrative concession has been shifting towards e-procurement processes by providing transparent electronic portals. This research aims, precisely, at encouraging a better understanding of how information technology may have systemic benefits to public bodies aiming to efficiently conduct a digital procurement ecosystem. To do this, the authors have analyzed the 23 PSO routes imposed so far, and the corresponding administrative procedures. The findings suggest that e-procurement has led to greater public transparency.
\end{abstract}

Keywords: EU single market; aviation; transportation; public service obligation; information technology; digital procurement ecosystem

\section{Introduction}

Transportation plays an essential role in ensuring the free mobility of goods and individuals that, together with services and capital, provide the four freedoms of the European single market. The air transport market has achieved great liberalization with a high level of openness, being one of the most convincing cases of success in its internal market. However, the benefits of opening the market have not always reached all regions across the European Union (EU), such as peripheral and remote territories, and isolated areas. Given the fact that the enhancement of sustainable mobility usually has a positive social impact, the existence of adequate means of transport may also ensure regional development in terms of territorial cohesion within the EU. But the free-market regime can lead to a territorial disadvantage when there is a lack of competition on specific air routes. In such instances, several member states have strongly used the imposition of public service obligation (PSO) 
to ensure the availability and continuity of operation on concerned scheduled air routes. As the PSO schema creates a distortion on the EU liberalized air transport market, this form of public intervention must be duly justified, particularly when this refers to a closed PSO with compensation (the most restrictive type). In this context, this paper tries to show how information technology has helped public bodies to announce information notices, such impositions and invitations to tender, related to PSO air routes imposed in Spain, for the sake of public transparency. Furthermore, this research aims to look beyond these administrative processes to understand how public administrations have committed themselves to streamlining procurement processes through electronic public procurement and announcement platforms. To this end, this study focuses on issues related to PSO schema within the competence of public authorities regarding this type of administrative concession on scheduled air routes in Spain, in particular, those concerning the PSO restricted to one carrier with compensation. For this reason, the authors have analyzed the evolution of PSO impositions on regular air services in Spain by consulting the pertinent documentation related to these administrative proceedings at a national level. The authors also based their research on a source of community-level data in order to obtain further information on the PSO schema across the EU. In parallel with the consultation of documents through public information sources, the authors have searched other trusted sources in order to access alternative data on this matter. After requesting specific, relevant information for this investigation, the authors enriched their understanding of the procurement processes related to PSO impositions. One of the findings of this study precisely yields that tender processes related to PSO air routes have shortened the time required to award a public contract, partly as a result of public electronic procurement platforms. In this regard, a total of 17 tendering procedures related to PSO impositions were announced, as well as corresponding contracts for a total of EUR 58,178,029 awarded, within the period from 25 March 2014 to 21 August 2019 through the unified portal existing in Spain, while ten of them have exclusively been managed via an electronic tender system through public e-procurement. Bearing in mind that the PSO schema includes 176 air routes across $14 \mathrm{EU}$ member states (as of 18 September 2019), the scope of this research has been limited to a case study of PSO air routes in Spain. Furthermore, because public bodies conduct administrative procedures related to the PSO system not only at national level but also at a regional level, there is a substantial heterogeneity in the management of the imposing and tendering process for PSO air services, depending on the level of information technology resources devoted to these public procedures in every EU member state. Moreover, pursuant to the Regulation of the European Commission (EC) no. 1008/2008, notices relating to the PSO system, such as impositions, modifications and abolitions thereof, and even calls for tender, must be published in the Official Journal of the European Union (OJEU). Nevertheless, the national administrations hold certain autonomy in the tendering and awarding process of public contracts for PSO air services. In this concern, the tender process of PSO public contracts among EU member states differs in the scope of transparency: for instance, from a fully transparent procedure such as the e-procurement system of the Spanish imposition on the air route LEI-SVQ to the Lithuanian imposition on the air route LCY-VNO, on which information regarding bids, the expected number of passengers, or the amount of compensation is considered by airport authorities to be confidential. For this reason, the main question throughout this paper investigates whether the use of electronic platforms based on information technologies results in the enhancement of the transparency and efficiency of public procurement processes. Consequently, the observed benefits associated with the establishment of e-procurement systems on PSO matters have a positive impact on public policies for e-government as part of the current fourth industrial revolution. Moreover, it has been recognized that the connectivity needs of certain regions within the EU represent such an objective, and therefore, a PSO can be imposed to meet specific well-defined public needs. In all cases, such imposition and design of a PSO route has always to meet the criteria set out in EU regulations, in addition to national laws. In the case of Spain, the civil aviation authority, named Dirección General de Aviación Civil (hereafter DGAC), on behalf of the Ministry of Public Works (currently named Ministerio de Transportes, Movilidad y Agenda Urbana, formerly Ministerio de Fomento), has the mandate to design the imposition of PSO on air 
routes of the domestic market, as well as to carry out the corresponding procurement procedures for awarding the public contract of regular air services.

\section{Background of the Public Service Obligation Schema}

Unlike the liberalization of the aviation industry in the American domestic market, the so-called "Airline Deregulation Act 49 USC 1301 of 1978", the opening of the air market in the EU has been sustained by a package of economic liberalization measures. Consequently, the national rule-making framework gave rise to common EU legislation through three packages of liberalization measures. These packages were consecutively implemented in 1987, 1990, and 1992, which has allowed for a consistent set of regulations within the European aviation area. Since the liberalization of air services, the air transport industry in the EU single market has enjoyed a high level of competitiveness and efficiency linked to the high standards of safety in its operations. Air passengers have benefited from lower fares and more routes within the internal market, whilst airlines have addressed strong cost adjustments due to a strong pressure on air travel pricing in a tough competitive environment. In recent years, the price competition in the European air transport market has been increasing. In addition, air carriers have been making extraordinary efforts in order to control and lower operational costs. As a result, airlines have significantly increased their actions in order to reformulate their business strategies by focusing on high-yield routes, which would make their operations economically highly profitable. This has led airlines to cut non-hub routes, particularly those linking to regional airports, and even to withdraw from peripheral areas. Unfortunately, some airlines were not able to adapt to new market realities, and therefore were driven to collapse. In fact, in the last few years the number of airlines going bankrupt has drastically increased compared to the amount of newer scheduled carriers in the European aviation market [1]. Despite the further expansion in supplying air routes subject to free market rules, the liberalization of the aviation market has not avoided the fact that airlines have still reduced flights and abandoned some air routes altogether, mainly those on domestic markets. Thus, the PSO schema has arisen in response to the needs of the population living in peripheral or remote territories, whose airports are not being sufficiently serviced by airlines. Although they are operating under a system of free competition, airlines might not be attracted to serve some routes in terms of public service. When this happens, a PSO may be imposed on regular air routes under certain circumstances. Nevertheless, PSO impositions in the aviation sector represent a limitation on the freedom to provide services. In line with the Treaty on the Functioning of the European Union (hereinafter called TFEU), the freedom to provide services is one of the fundamental four freedoms of its internal market. Consequently, any such limitation has to be strictly limited in scope and proportionate to the desired objective. This form of public intervention has played a fundamental role in developing regional airports, especially medium-sized airports serving narrow scheduled routes. As can be seen from Table 1, within the PSO schema, three cases can be distinguished depending on whether the route is open or closed to one carrier. Furthermore, if a carrier receives compensation from public funds at a national, regional, or local level for the provision of PSO services, it also must comply with member state aid rules.

The current legal basis for the PSO schema within the European single market in aviation has been enshrined in articles 16-18 of Regulation (EC) no. 1008/2008 of the European Parliament and of the Council of 24 September 2008 on common rules for the operation of air services in the Community (hereinafter called Air Services Regulation 1008/2008). Previously, the concept of PSO had been introduced under Council Regulation of the European Economic Community (EEC) no. 2408/92 of 23 July 1992 on access for Community air carriers to intra-Community air routes and whose article 4 established a basic regime for the PSO system. However, in both regulations, reforms are still pending to enhance this form of public intervention in the internal air market. Specifically, there are certain aspects related to the public transparency of procurement procedures for contracts for PSO services. Moreover, the question of funding has still not been fully resolved in order to consolidate a common fund at the Community level. On this aspect of the former legislation, it has been recommended that 
procurements for PSO contracts should be mainly carried out and funded at EU level [2]. More recently, upon the entry into enforcement of the current air services regulation, it was argued that a common model for the PSO schema, directly administrated at Community level, could become over-regulated for both political and legal reasons, and even interfere with national interests for public services [3].

Table 1. Summary of public service obligation (PSO) schema on the Single Aviation Market (as of 18 September 2019).

\begin{tabular}{cccccc}
\hline $\begin{array}{c}\text { EU Member } \\
\text { State }\end{array}$ & $\begin{array}{c}\text { Total Number of } \\
\text { PSO Air Routes }\end{array}$ & $\begin{array}{c}\text { Annual PSO } \\
\text { Subsidization } \\
\text { (in Millions of EUR) }\end{array}$ & $\begin{array}{c}\text { Open PSO with } \\
\text { Operating } \\
\text { Requirements } \\
\text { (Type 1) }\end{array}$ & $\begin{array}{c}\text { Closed PSO } \\
\text { without Any } \\
\text { Compensation } \\
\text { (Type 2) }\end{array}$ & $\begin{array}{c}\text { Closed PSO } \\
\text { with Economic } \\
\text { Compensation } \\
\text { (Type 3) }\end{array}$ \\
\hline France & 37 & 92.16 & 9 & 0 & 28 \\
Greece & 28 & 8.30 & 8 & 3 & 17 \\
Spain & 23 & 17.26 & 15 & 0 & 8 \\
UK & 22 & 15.05 & 0 & 0 & 16 \\
Portugal & 20 & 30.79 & 4 & 0 & 9 \\
Italy & 11 & 52.08 & 0 & 2 & 11 \\
Sweden & 11 & 16.98 & 0 & 0 & 3 \\
Croatia & 10 & 13.88 & 0 & 0 & 3 \\
Estonia & 3 & 2.67 & 0 & 0 & 3 \\
Ireland & 3 & 8.32 & 0 & 0 & 0 \\
Finland & 3 & 3.22 & 0 & 0 & 1 \\
Czechia & 3 & 0.84 & 1 & 0 & 0 \\
Cyprus & 1 & 0.00 & 0 & 0 & 3 \\
Lithuania & 1 & 4.90 & 0 & 0 & 0 \\
\hline
\end{tabular}

${ }^{1}$ Own work based on latest data available [4]; ${ }^{2}$ Applicable for PSOs under type 3 only.

As the European aviation sector has been fully deregulated in accordance with Article 100(2) of the Treaty on the Functioning of the European Union (TFEU), the European Commission (EC) has consistently worked towards strengthening the EU single market for air services, including advocating the extension of its scope to certain nonmember countries with geographical proximity. Since the maintenance of an adequate transportation network usually requires promotion through EU common public policies aiming at improving regional development in terms of territorial and social cohesion, the EU member states have looked for a way to meet this essential need for public service without interfering with free competition. Strictly speaking, the imposition of a PSO on a particular scheduled air route can be regarded as a public intervention on the transportation market. While it is true that the long-term implications of the PSO schema in terms of sustainability and efficiency have not widely been researched, some recent work have tried to shed more light on this matter based on certain case studies concerned, for instance, with the case of Norway with regard to social efficiency measures by determining the level of service (LOS) [5], or a welfare perspective by modelling a socially-oriented analysis for flight scheduling and fleet assignment [6] (please note that Norway, as well as Iceland and Liechtenstein, despite not being an EU state member, is part of a broad agreement with the EU to act as part of its single market with exceptions through the European Economic Area (EEA), and therefore assumes compliance with EU law). Other earlier work has sought to gain a deeper understanding of the public impact due to the existence of the PSO schema in low-populated areas. In the case of Italy, the efficiency of accessibility in remote regions served by the PSO schema has been analyzed through comparison with different transport alternatives [7]. In the case of Portugal, the research question has been raised of whether the local network's operating costs can be reduced in order to achieve greater efficiency in applying subsidies on PSO air routes [8]. All of this reflects that the maintenance of an adequate transportation network usually needs to be promoted through EU common public policies aiming at improving regional development in terms of territorial and social cohesion. In this respect, with regard to the scope of the present paper, the air passenger transportation system serving Spanish remote territories has traditionally been suffering from weaknesses in domestic demand because of high seasonality that undermines the profitability of certain regular air services. As discussed later, 
particular thin regular routes in Spain have been identified as an essential transport service, and thus this has forced the imposition of a PSO for ensuring affordable and accessible air transportation.

\subsection{Legal Considerations}

The current legal basis for the PSO schema within the European single market in aviation was enshrined in articles 16-18 of Regulation (EC) no. 1008/2008 of the European Parliament and of the Council of 24 September 2008 on common rules for the operation of air services in the Community (hereinafter called Air Services Regulation 1008/2008). Previously, the concept of PSO had been introduced under Council Regulation (EEC) No 2408/92 of 23 July 1992 on access for Community air carriers to intra-Community air routes and whose article 4 established a basic regime for the PSO system. However, in both regulations, reforms are still pending to enhance this form of public intervention in the internal air market. There are certainly some domestic legal issues concerning the public transparency of procurement procedures for contracts for PSO services that pose difficulties in aligning with the government tender system among member states. Additionally, the question of funding has still not been fully resolved in order to consolidate a single frame at Community level. Since Air Services Regulation 1008/2008 does not specify tender directives for an efficient procedure of public procurement in awarding PSO contracts, it seems that member states are free to adopt calls for tenders from an electronic platform either at national or regional level without being obligated to make public all the procurement documents and performance reports concerned. In this regard, it is to be expected that an impact assessment report can be finalized by the Commission, and then published within the shortest possible time. Once the corresponding staff working document has been revised, a legislative proposal should be drafted to modify Air Regulation No 1008/2008. These changes are likely to further affect the PSO provisions, particularly those concerning the length of the tendering period and the amount of information to be published in public notices. This will entail a significant improvement in regulatory monitoring capacity along with greater transparency that can be used for tendering and contracting from related public authorities to the air carriers concerned.

\subsection{Economic Considerations}

As the PSO schema is supposed to become an instrument for ensuring the existence of adequate air services serving peripheral areas or development regions, it is fundamental to have transparent and unambiguous criteria for defining when air routes are eligible to be imposed as PSO services. Nevertheless, under Air Services Regulation 1008/2008, it does not state clearly what is meant by eligible territories for PSO impositions in the context of economic development. In order to address that concern, the Commission provided a notice with further clarification of the current PSO regulation, also named 2017/C 194/01, from the Official Journal of the European Union (OJEU). Thus, the criteria traditionally used to determine whether a territory is a development region are based on the evaluation of gross domestic product (GDP) per capita (e.g., when purchasing power parity (PPP) is less than $75 \%$ of the EU average) or the unemployment rate [9]. However, there are still aspects that require further improvements, such as those related to common rules for subsidies, airfares, and tenders, in order to achieve a regional air transport system as a viable supporting factor for regional economic advancement [10], and therefore to avoid inconsistencies in designing social air routes [11]. From a strictly economic-related point of view, the objective of the air passenger market should be to match supply with demand for regular services in the most efficient way and so to give individuals the best possible means of transport to meet their mobility needs. The provision of public regular air services requires, therefore, a focus that goes further than the needs of the domestic market, since the imposition of a PSO on certain air route interferes in the EU's single market for transportation services. In the event that such disruption to the market does occur, the possible adverse effects on free competition should be analyzed in depth to avoid unnecessary market distortions. With remote territories and peripheral areas, there is usually no choice but to use the PSO schema, whether it is imposed as a way of regulating or subsiding, or even both, the scheduled air services needed to ensure the maintenance 
of adequate mobility. When such market failure is identified, the imposition of a PSO in combination with related subsidization may be required to ensure essential air transport services in the most efficient manner. Unfortunately, the previous literature relating to economic efficiency in awarding PSO contracts is very scarce and probably insufficient so far, and even non-existent when the subject concerns e-procurement procedures.

\section{The PSO Schema on the Domestic Air Transport Market in Spain}

With a population of 47,026,208 (as of 1 January 2019), Spain holds the second greatest surface area in the EU, leading to a low population density compared with the European average. Traditionally, the unequal distribution of economic opportunities throughout the Spanish territory, defined by an extensive coastline, as well as a rugged terrain and a scattered population, has created an imbalance among regions, particularly those related to low-demand transportation networks. For territories with peripheral or remote nature, mobility needs are inherent in promoting the use of public service transport, simply by the fact of facilitating sustainable and adequate means of transport. When alternative modes of transport such as rail, bus, or ferries, or the combination of these, cannot be considered for reasons of travel time, frequency or price, or even a lack of such services, the design of a PSO air route often represents the most reasonable choice in terms of economic and social benefits. In Spain, the most restrictive case of PSO impositions, here called type 3, has not been used widely in designing PSO air routes, as seen in Table 2. Nevertheless, Table 3 shows a trend in the past few years towards imposing $\mathrm{PSO}$ on regular air routes restricted to one carrier, and consequently an increase in the number of tender process related to awarded public contracts for air services (Airlines and Airports see Appendix A). Furthermore, the number of bids submitted against invitations to tender for PSO contracts announced in Spain so far has almost always been one bidder for each bidding process. The domestic transport market of PSO air routes is thus highly concentrated among a few airlines, all of them headquartered in Spain. In fact, some tender procedures of contracts for PSO air services have been declared void in the lack of any bidder, as happened in the public biddings for the cases no. 155/A14 and no. 209A19 (refer, respectively, to Tables 3 and 4 . When this occurs, as in both of these cases, aviation authorities are forced to enhance the requirements contained in the bid documentation in order to make it more appealing to potential bidders by preparing a new announcement of invitation to tender. It is clear that aspects of the language and culture of bidders are not a detriment to cross-border competition for PSO air service contracts [12]. It is equally true that the specific features thereof, in addition to the complexity of operating at certain aerodromes with particular restrictions, such as those related to runway length or operational flight rules, have resulted in submitting tenders that were bid by domestic airlines only. This is precisely the case with all PSO routes tendered in Spain. Specifically, in none of the PSO air routes under type 3, for a total of 23 impositions (refer to Table 2), was there any bidder in any public competition from other EU member states.

Domestic carriers have played a fundamental role in operating PSO air routes related to low-demand regions. Without them, the mobility of people and goods would not be possible not only on routes serving remote territories, but also on thin ones. The socio-economic impact of the PSO schema on peripheral regions, including disadvantaged ones, is beyond any doubt. Prior research studies have shown how the PSO schema has proven to be very useful in serving some regional airports with a high degree of dependency on scheduled air services within the corresponding domestic markets, such as the case of the Canary Islands [13], the Azores [14], and the air routes between the Italian mainland and the island of Sardinia [15]. In contrast, concerns have been raised regarding the long-term sustainability of the regional airports, such as in the case of Ireland [16]. In the case of Spain, PSOs have been instrumental in growing the regional economy and regional development by providing communities with a fast means of transport. Such a form of public intervention on the internal air market has coexisted with price discounts not only for island residents (the Balearics and the Canaries), but also for those living in isolated areas (Melilla and Ceuta). In the case of the Canaries, this may even guarantee the profitability of PSO air routes in spite of their lower elasticity of 
demand [17]. Additionally, the existence of a dense airport network of nearly 47 operational facilities (as of 31 December 2019), 43 airports and two heliports managed at national level, in addition to two local airports, one of them privately managed and the other regionally managed, might explain the likely effect of expansion in the domestic flight supply from a deconcentrating pattern due to the growth of low-cost carriers at small and medium-sized airports [18]. It can be said that the main criterion of public investment in airport infrastructure has been established on the basis of enhancing territorial cohesion, and mainly from policies based more on social benefits than cost-benefit analysis. It may be wondered how air transport should be encouraged in assessing socio-economic footprint [19].

Table 2. Summary of PSO system on the Spanish domestic air transport market (as of 18 September 2019).

\begin{tabular}{|c|c|c|c|c|c|}
\hline Route Code & Airport & IATA Code & Airport & IATA Code & Type of PSO \\
\hline ES01 & Almeria & LEI & Sevilla & SVQ & 3 \\
\hline ES02 & Menorca & MAH & Ibiza & IBZ & 1 \\
\hline ES03 & Menorca & MAH & Madrid & MAD & $3 *$ \\
\hline ES04 & P. Mallorca & PMI & Ibiza & IBZ & 1 \\
\hline ES05 & P. Mallorca & PMI & Menorca & MAH & 1 \\
\hline ES06 & Gran Canaria & LPA & El Hierro & VDE & 3 \\
\hline ES07 & Gran Canaria & LPA & Tenerife S. & TFS & 3 \\
\hline ES08 & Gran Canaria & LPA & Fuerteventura & FUE & 1 \\
\hline ES09 & Gran Canaria & LPA & Lanzarote & $\mathrm{ACE}$ & 1 \\
\hline ES10 & Gran Canaria & LPA & Tenerife N. & TFN & 1 \\
\hline ES11 & Gran Canaria & LPA & La Palma & SPC & 1 \\
\hline ES12 & La Gomera & GMZ & Gran Canaria & LPA & 3 \\
\hline ES13 & La Gomera & GMZ & Tenerife N. & TFN & 3 \\
\hline ES14 & La Palma & $\mathrm{SPC}$ & Lanzarote & ACE & 1 \\
\hline ES15 & Tenerife N. & TFN & El Hierro & VDE & 1 \\
\hline ES16 & Tenerife N. & TFN & Fuerteventura & FUE & 1 \\
\hline ES17 & Tenerife N. & TFN & Lanzarote & ACE & 1 \\
\hline ES18 & Tenerife N. & TFN & La Palma & $\mathrm{SPC}$ & 1 \\
\hline ES19 & Badajoz & $\mathrm{BJZ}$ & Madrid & MAD & 3 \\
\hline ES20 & Badajoz & BJZ & Barcelona & $\mathrm{BCN}$ & 3 \\
\hline ES21 & Melilla & MLN & Almeria & LEI & 3 \\
\hline ES22 & Melilla & MLN & Granada & GRX & 3 \\
\hline ES23 & Melilla & MLN & Sevilla & SVQ & 3 \\
\hline
\end{tabular}

Source: compilation based on data from [4]; additional information provided by DGAC upon request. Explanatory note: International Air Transport Association (IATA); * in seasonal periods only.

\section{Background of Procurement System for PSO Provision}

Considering "Directive 2014/24/EU of the European parliament and of the Council of 26 February 2014 on public procurement and repealing Directive 2004/18/EC", the use of electronic means in designing the procurement management process should be promoted by all member states, once the provision of this EU directive has been integrated into the corresponding national legislation. Regarding tender processes concerning PSOs restricted to one carrier (type 3), there are not many rules in the regulation of the tendering process, and therefore there is no guidance on it either. While it is desirable to provide call for tender available electronically, some of them may still be paper-based. In the last few years, indeed, there has been a significant increase in the number of PSO impositions (type 3) across the EU, and not all of them follow strictly the same methodology. Procurement procedures for the provision of PSO services depend on national regulations, as Air Regulation no. 1008/2008 gives no further indication in this respect. Despite the existence of a guide to good practices for the PSO system, also named "Interpretative Guidelines on Regulation (EC) No 1008/2008", this document explicitly excludes the procurement of air services from its scope (refer to points 113 and 114 of [9]). Although Directive 2014/23/EU of the European Parliament and of the Council of 26 February 2014 describes procedural aspects related to the award of concession contracts, public procurement directives are not in the remit of Department for Mobility and Transport (DG MOVE), and therefore the PSO tender procedures may not necessarily be aligned to each other. In fact, the Air Services Regulation 
(refer to Article 17(9)) only obliges member states to inform DG MOVE about the results of both the tender and the selection. Unfortunately, nothing is mentioned in the regulation about PSO provision by using cross-border free open sources, such as the e-Prior. However, thanks to the promotion of e-procurement, it is foreseeable that tenders among EU countries can become fully transparent and permanently monitored without any restriction.

\section{Results}

This section intends to provide readers with an overview of the results obtained from the analysis and study of the features of procurements related to invitations to tender for PSO air services. As noted previously, the PSO schema comprises three modalities of air routes, depending on whether they have been imposed as an open PSO (type 1), as a closed PSO with exclusivity and without compensation (type 2), or as a closed PSO route with both exclusivity and compensation (type 3). Hence, both types 2 and 3 are necessarily linked to tendering procedures. However, for the scope of this research, the discussion will be focused on the PSO routes under type 3 that have been imposed in Spain thus far. As seen in Table 3, the Spanish PSO domestic market has traditionally been characterized by non-indiscriminate use of the tendering process for PSO contracts, instead massively setting routes restricted to one carrier as the first choice for PSO provision, except in the case of low-demand routes. In fact, PSO impositions have greater flight frequencies than those on unprotected passenger air services, particularly on low demand routes [20]. Most recently, the lack of airlines willing to operate under an open PSO has led to the design of such routes as public routes under the most restrictive type. Studying the evolution of PSO air routes in Spain, it can also be found that, in addition to a sharp increase of impositions in recent years, the provision of related procurement procedures has grown substantially over the past few years. This research highlights, therefore, the strong commitment made by public authorities with regard to considering such air routes as essential services.

Table 3. Summary of tender processes for PSO impositions (as of 31 December 2019).

\begin{tabular}{|c|c|c|c|c|c|c|c|}
\hline $\begin{array}{l}\text { Route } \\
\text { Code }\end{array}$ & $\begin{array}{l}\text { Passengers } \\
\text { Carried } \\
\text { (in Thous.) }\end{array}$ & $\begin{array}{l}\text { Contract } \\
\text { Duration } \\
(\text { mos. })^{a}\end{array}$ & $\begin{array}{l}\text { CAGR } \\
(\%)^{b}\end{array}$ & $\begin{array}{c}\text { Public Aid } \\
\text { (in Thous. of EUR) }^{c}\end{array}$ & $\begin{array}{c}\text { Ratio } \\
(\text { EUR/PAX) }\end{array}$ & $\begin{array}{c}\text { Level of } \\
\text { Implementation } \\
\text { (Ratio) }^{e, i i}\end{array}$ & $\begin{array}{c}\text { Air Carrier } \\
\text { (IATA Code) }^{f}\end{array}$ \\
\hline ESO2 & 119.3 & $\mathrm{n} / \mathrm{a}$ & 6.7 & $\mathrm{n} / \mathrm{a}$ & $\mathrm{n} / \mathrm{a}$ & $\mathrm{n} / \mathrm{a}$ & YW, UX \\
\hline ES03 & 3777.1 & 40 & 1.0 & 9440.3 & 2.49 & $4: 8$ & YW \& IB \\
\hline ES04 & 6252.2 & $\mathrm{n} / \mathrm{a}$ & 0.8 & $\mathrm{n} / \mathrm{a}$ & $\mathrm{n} / \mathrm{a}$ & $\mathrm{n} / \mathrm{a}$ & YW, UX \\
\hline ES07 & 1500.5 & 40 & 1.6 & 2932.4 & 1.95 & $0: 3$ & NT \\
\hline ES08 & 8628.7 & $\mathrm{n} / \mathrm{a}$ & 0.3 & $\mathrm{n} / \mathrm{a}$ & $\mathrm{n} / \mathrm{a}$ & $\mathrm{n} / \mathrm{a}$ & NT, PM, UX \\
\hline ES09 & 9348.5 & $\mathrm{n} / \mathrm{a}$ & 0.7 & $\mathrm{n} / \mathrm{a}$ & $\mathrm{n} / \mathrm{a}$ & $\mathrm{n} / \mathrm{a}$ & NT, PM, UX \\
\hline ES10 & $11,463.9$ & $\mathrm{n} / \mathrm{a}$ & 1.0 & $\mathrm{n} / \mathrm{a}$ & $\mathrm{n} / \mathrm{a}$ & $\mathrm{n} / \mathrm{a}$ & NT, PM, UX \\
\hline ES11 & 1841.5 & $\mathrm{n} / \mathrm{a}$ & 1.0 & $\mathrm{n} / \mathrm{a}$ & $\mathrm{n} / \mathrm{a}$ & $\mathrm{n} / \mathrm{a}$ & NT \\
\hline ES16 & 3172.1 & $\mathrm{n} / \mathrm{a}$ & 1.1 & $\mathrm{n} / \mathrm{a}$ & $\mathrm{n} / \mathrm{a}$ & $\mathrm{n} / \mathrm{a}$ & NT, PM, UX \\
\hline ES17 & 4456.5 & $\mathrm{n} / \mathrm{a}$ & 0.9 & $\mathrm{n} / \mathrm{a}$ & $\mathrm{n} / \mathrm{a}$ & $\mathrm{n} / \mathrm{a}$ & NT, PM, UX \\
\hline ES18 & 9296.2 & $\mathrm{n} / \mathrm{a}$ & 0.6 & $\mathrm{n} / \mathrm{a}$ & $\mathrm{n} / \mathrm{a}$ & $\mathrm{n} / \mathrm{a}$ & NT, PM, UX \\
\hline ES19 & 364.3 & 18 & 0.4 & 4084.5 & 11.21 & $1: 1$ & YW \\
\hline ES20 & 390.9 & 18 & 0.4 & 4084.5 & 10.44 & $1: 1$ & YW \\
\hline ES21 & 278.2 & 8 & -0.7 & 506.1 & 1.81 & $1: 1$ & YW \\
\hline $\mathrm{ES} 22$ & 234.1 & 8 & 0.3 & 506.1 & 2.16 & $1: 1$ & YW \\
\hline ES23 & 22.2 & 8 & -0.2 & 506.1 & 22.79 & $1: 1$ & YW \\
\hline$\Sigma$ & $69,195.2$ & $\mathrm{n} / \mathrm{a}$ & $\mathrm{n} / \mathrm{a}$ & $67,662.4$ & $\mathrm{n} / \mathrm{a}$ & $\mathrm{n} / \mathrm{a}$ & $\mathrm{n} / \mathrm{a}$ \\
\hline$\overline{\mathrm{A}}$ & 3008.5 & 45.45 & 1.2 & 6184.5 & 19.55 & $\mathrm{n} / \mathrm{a}$ & $\mathrm{n} / \mathrm{a}$ \\
\hline
\end{tabular}


Table 4. Summary of tenders for PSO routes without full e-procurement process (as of 31 December 2019).

\begin{tabular}{|c|c|c|c|c|c|c|c|c|c|}
\hline $\begin{array}{l}\text { Route } \\
\text { Code }\end{array}$ & 322/A09 & 197/A12 & 108/A14 & $\begin{array}{c}108 \\
\text { BIS/A14 }\end{array}$ & 138/A14 & $\begin{array}{c}\text { 155/14 } \\
\text { BIS }\end{array}$ & 155/A14 & 20/A16 & 46/A16 \\
\hline $\begin{array}{l}\text { ES01 } \\
\text { ES02 } \\
\text { ES03 } \\
\text { ES04 } \\
\text { ES05 } \\
\text { ES06 } \\
\text { ES07 } \\
\text { ES08 } \\
\text { ES09 } \\
\text { ES10 } \\
\text { ES11 } \\
\text { ES12 } \\
\text { ES13 } \\
\text { ES14 } \\
\text { ES15 } \\
\text { ES16 } \\
\text { ES17 } \\
\text { ES18 } \\
\text { ES19 } \\
\text { ES20 } \\
\text { ES21 } \\
\text { ES22 } \\
\text { ES23 }\end{array}$ & $\bullet$ & $\bullet$ & • & • & $\bullet$ & - & • & $\begin{array}{l}\bullet \\
\bullet \\
\bullet \\
\bullet\end{array}$ & $\bullet$ \\
\hline $\begin{array}{l}\text { Budget } \\
\text { (EUR) }^{a}\end{array}$ & $11,900,000$ & $2,400,000$ & $6,200,000$ & $6,200,000$ & $9,074,050$ & $2,400,000$ & $2,400,000$ & $5,581,000$ & $2,071,835$ \\
\hline $\begin{array}{l}\text { Duration } \\
(\text { mos. })^{b}\end{array}$ & 48 & 16 & 16 & 16 & 48 & 16 & 16 & 24 & 16 \\
\hline $\begin{array}{c}\text { Execution } \\
(\%)^{\mathrm{c}}\end{array}$ & 100 & 68.8 & 0 & 100 & 100 & 100 & 0 & 100 & 100 \\
\hline
\end{tabular}

Source: Own elaboration based on [21,22]. Figure notes: ${ }^{a}$ Maximum budget estimated to meet the funding gaps for PSO operations; ${ }^{b}$ Duration of the service defined on the PSO contract; ${ }^{c}$ Current degree of execution of PSO contract. Explanatory note: Black circle "•" denotes a route with procurement procedure applicable to a PSO contract, while blank space indicates "not applicable".

\subsection{Overview of Tenders Related to Imposition of PSO without Full E-Procurement Procedure}

At the beginning of the implementation of the PSO system in Spain, there was no obligation to post on a unified online platform documents relating to procurements for the provision of PSO air services. Hence, procurement procedures for the purpose of awarding a contract for PSO imposition under type 3 were governed by Royal Legislative Decree 3/2011, in which was approved the recast text of the Public Sector Contracts Law 09/2017 (hereinafter LCSP). Only tender announcements, as well as those related to awards of PSO contracts, were thus subject to domestic law, and therefore published in the corresponding official gazettes. Despite this, some documents submitted by carriers in order to bid in a tender procedure were not permitted to be accessed by anyone, and therefore were restricted for reasons of confidentiality. Covering the period from 2009 to 2016, as shown in Table 4, the time taken to award PSO contracts, with the exception of those with unsuccessful tenders, was approximately two years. Apparently, such public procedures were time-consuming tasks due in part to the lack of a compulsory tender system for complete electronic processing that would have facilitated the use of electronic tools, thereby eliminating the need to use physical documents.

\subsection{Overview of Tenders Related to Imposition of PSO with Full E-Procurement Procedure}

In Spain, upon the entry into force of Law 09/2017 of 8 November on Public Sector Contracts, the so-called Ley 09/2017 de 8 de noviembre, de Contratos del Sector Público (hereinafter new LCSP), which was the result of the transposition of directives of the European Parliament and of the Council of 
21 February 2014 (2014/23/UE and 2014/24/UE), procurement management on the PSO system achieved much better performance in terms of transparency and openness thanks to the implementation of a unified procurement platform, commonly referred to as the Plataforma de Contratación del Sector Público (hereinafter PLACSP). As a result, documents relating to any tender process must be posted on PLACSP regardless of which public authority manages it. Irrespective of whether the economic compensation for a PSO air service is directly provided at national level (e.g., air route E03), or, failing this, at regional level (e.g., air route ES01), the award of the corresponding contract involves the use of the PLACSP not only by the national aviation authority, but also by bidders that expect to win a competitive tender to carry out regular air services on the PSO route. This contributes to increasing the flexibility of these procedures. In fact, Table 5 illustrates precisely how often PSO contracts have successfully been awarded under the e-procurement system.

Table 5. Summary of tenders for PSO routes with full e-procurement process (as of 31 December 2019).

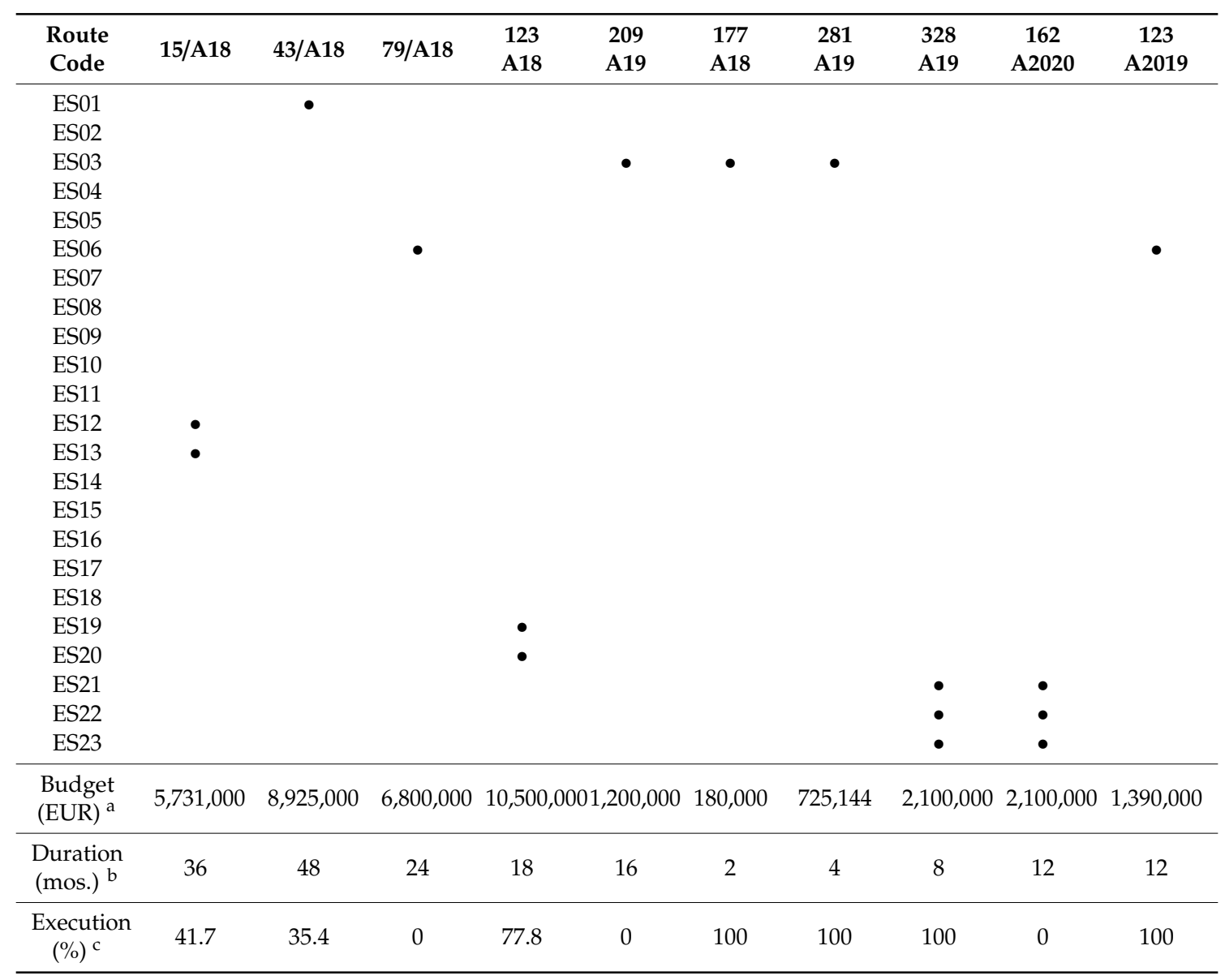

Source: Own elaboration based on [21,22]. Figure notes: ${ }^{a}$ Maximum budget estimated to meet the funding gaps for PSO operations; ${ }^{b}$ Duration of the service defined on the PSO contract; ${ }^{c}$ Current degree of execution of PSO contract. Explanatory note: Black circle "•" denotes a route with procurement procedure applicable to a PSO contract, while blank space indicates "not applicable".

\section{Discussion}

As already pointed out, the promotion of public transport plays a key role in the European common policy for implementing a sustainable mobility model, and thus enforcing best practices by fighting against climate change. To this end, the European Commission (EC) has consistently advocated the establishment of an integrated transportation network by supporting the development of multimodality. In certain European peripheral regions, specifically those located far away from main transportation hubs, air transport may better meet administrative requirements with regards to frequencies and capacities. In such cases, the establishment of scheduled air services, besides being 
more convenient, could also become the optimal solution to ensure adequate public means of transport, particularly those serving remote territories. In that context, air transport is therefore not only the most appropriate rapid means for carrying people and goods in remote areas, but also the only possible method for island territories. Considering that the EU single market in aviation has been gradually liberalized, European airlines are already entitled to freely establish and provide air services in any place in the internal market they choose, even on domestic routes, without restrictions, on the basis of a valid air operator's certificate (AOC) from any EU member state. However, scheduled air services in a free market regime have not always adequately served due to a lack of competition or even private initiative in operating on thin air routes, in addition to those serving peripheral areas. The PSO schema has been shown to be a useful mechanism to solve such market failure. Earlier studies, in spite of not being numerous, have found evidence pointing to the importance of the PSO schema in terms of efficiency, for instance, by analyzing certain determinants from a semi-parametric approach [23] and considering the level of service in terms of social efficiency [5]. As administrative procedures for imposition of a PSO on a certain air route can involve specific technical and operational requirements, particularly those related to awarding tenders, current European legislation seeks to safeguard free competition in a single market economy while promoting adequate public transportation, and thus facilitating free mobility. In contrast, there is a risk that excess public intervention in allowing the imposition of a PSO on several routes may lead to the undermining of free competition in the internal air market. For that purpose, EU member states have been urged to avoid any obligation without due justification based on precise arguments as to proportionality to socioeconomic development needs, as well as to the inadequacy of alternative transport modes [9]. As the EU internal air market is already fully liberalized, confirmation of its public service nature has been addressed by earlier studies, such as those analyzing the social aspects of air transport [24], and also in previous studies that considered whether air transport is a necessity for social inclusion and economic development [25].

On a different point of discussion, it is also worth noting that the practices of carrying out the PSO tender process vary, since some member states do everything centrally and electronically with a national authority (as in the case of Spain, Greece, Croatia, Ireland, Lithuanian, Estonia, and Sweden), and in others procurements have been carried out at regional level (as in the case of Finland and the Czechia), or a mixture of both (as in the case of Portugal and Italy), or even at community level (as in the case of France and UK). As for the case of public contracts for PSO, it is expected that tenders should be subject to the procedures announced and awarded from the contracting electronic platform, also known as the e-procurement system. Unfortunately, Regulation no. 1008/2008 does not explicitly regulate this, but only applies the condition of universal free availability, either on paper or electronically, to those documents based on which tenders can be drafted. In fact, our research has long observed some gaps for possible future modification of EU Air Regulation in those aspects that would make it possible to achieve greater transparency of tender documents and the related explanatory reports. It might bring clarity to the issue of how the call for tenders can be managed more efficiently in order to achieve more simplified procedures. Hence, after an analysis of the 23 PSO routes imposed in Spain, as will be thoroughly seen over the following sections, it can be observed that e-procurement has been extensively used by DGAC in the whole administrative process relating to the imposition of PSO and related public contracts since. Given the fact that no previous studies have investigated the potential benefits of the information technologies used in electronic platforms for impositions of PSO on regular air services, particularly in the case of Spain, this research can serve as an avenue for future works. Herein lies the originality of this paper.

\subsection{Considerations on Findings about Public Tenders Relating to PSO Services on Air Route ESO1}

Some characteristics of the scheduled air services on the route SVQ-LEI make it a specific case of PSO imposition in the Spanish domestic air transport market. This route was the first imposition of PSO on a regular air route to link two airports within mainland Spain. As seen both in Tables 3 and 4, it was the most significant public procurement process for the awarding of PSO services under type 
3 within the Spanish domestic market, in terms of both the total volume awarded (EUR 28,349,124) and the total duration of the contracts (144 months), with up to a total of three tender procedures. In addition, the analysis of the efficiency and sustainability of this PSO route in an earlier paper showed that the imposition of a PSO on this route resulted in enhanced demand for air services, and specifically compensation from the procurement contract for regular air services [26]. As shown in Figure 1, since August 2014, scheduled air services have been guaranteed thanks to the succession of two fixed-term PSO contracts. This has enabled awarded the carrier (YW) to consolidate the supply of direct flights per the requirements of the invitation to submit a tender bid for such transport service. Based on the data from this research, the effect on the performance of such contracts in attracting passengers has been very positive. Moreover, according to our estimation, the budgetary savings compared with the award amount of the three successful tenders sum to a total of EUR 1,549,926. During the 2010-2019 period, the compound annual growth rate (CAGR) was 3.7\%. Within these years, this air service has been consolidated with the domestic market and it is a clear case according to the successful figures shown.

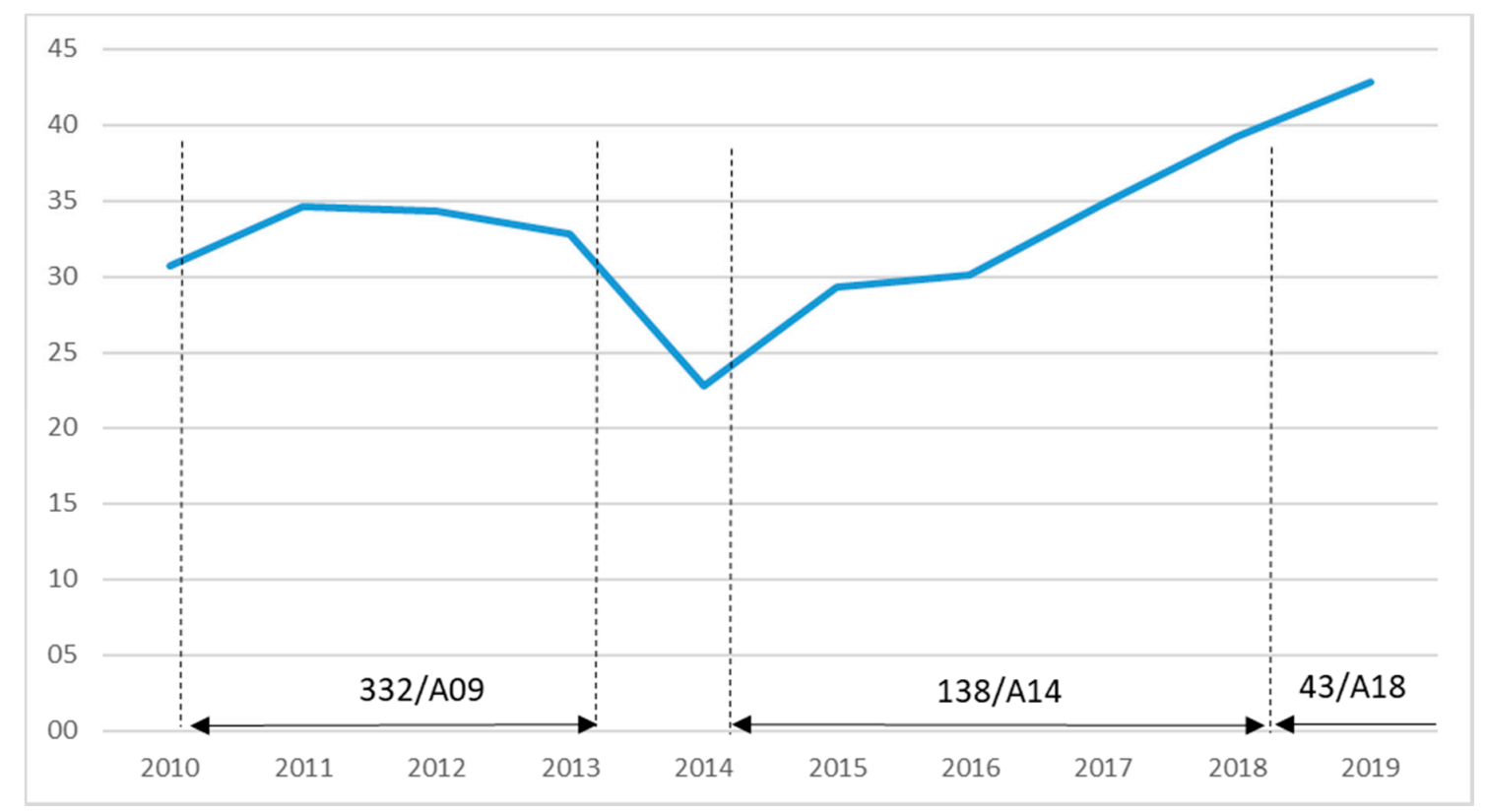

Figure 1. Thousands of passengers carried yearly on the PSO air route ES01 (as of 31 December 2019). Source: Own elaboration based on [21,22]. Explanatory notes: Each arrow denotes a contract period for a PSO type 3 with its respective case number for proper identification; where there is no arrow, this denotes a period of activity without any compensation (PSO type 1 or 2), or failing this, under free market conditions.

The continuity of PSO contracts such as 138/A14 and 43/A18 appears to have had a significantly decisive role in stimulating the demand for daily flights on this air route. The implementation of e-procurement in tendering the contract of 43/A18 has made it possible to maintain demand growth, while also ensuring efficient execution of related call for tender before ending the contract of 138/A14. In contrast, the lack of continuity in subsidization during the period between the 332/A09 and 138/A14 contracts led to a sharp drop in demand for flights on air route ES01. Clearly, the supply of air services (UX) on this route in a free market regime in such a period (from 14 January 2014 to 1 August 2014) did not have as good performance in terms of passengers as those transported under the PSO of type 3 .

\subsection{Considerations on Findings about Public Tenders Relating to PSO Services on Air Route ESO3}

This case relates to the only PSO imposed on an air route in Spain linking an airport serving an island territory and a major hub airport, these being Menorca (MAH) and Madrid (MAD), respectively. 
The flux of tourism tremendously influences the activity of air traffic on this island's airport at Mahon. This not only results in offering a wide range of direct flights from many European airports to the island airport, but also in creating a high seasonality for its air operations. This situation means that slot coordination at this airport has been classed, according to European laws such as Article 3 of EEC Regulation no. 95/93, later modified by EC Regulation no. 793/2004, in addition to corresponding national laws such as Article 4 of Royal Decree 20/2014, into two main categories depending on whether flights are operating in low season or high season. This creates a dual categorization each year as a facilitated and coordinated airport, respectively. Nevertheless, the singularity of such s PSO route resides more than anything in the high number of tender processes carried out in order to maintain adequate air transportation services for people living on the island of Menorca. Given the fact that such route was sufficiently served over previous years, there was no need to impose a PSO under type 3 . However, by the end of 2011 the number of passengers transported suddenly dropped. One of the causes of such a dramatic change in passenger traffic, as shown in Figure 2, could be attributed to the collapse of carriers operating in the Balearic Islands, such as Spanair (formerly JK) on 28 February 2012, and Air Berlin (formerly AB) on 28 October 2017. Then, the route suffered a reduction in regular flights, and was eventually withdrawn by Vueling (VY), Ryanair (FR), and Iberia Express (I2). In fact, the last carrier (YW) operating this route in the free market regime also considered leaving it, but only in the winter season. This suggests that PSO contracts would have to meet the needs of air transportation on this route, but only in the low season. Indeed, this is precisely the main difference from other PSO impositions in Spain, where that does not happen. In this concern, two tenders of eight total processes could have been successfully awarded, and four of them were carried out as e-procurements. Based on our findings, the settlement of such procurement procedures allowed the public authorities to save a total of EUR 880,886. In addition, since November 2012, the succession of short-term PSO contracts assured the provision of scheduled air services, in addition to continuous growth, made evident by the fact that the CAGR calculated is 5.8\% between 2013 and 2019 .

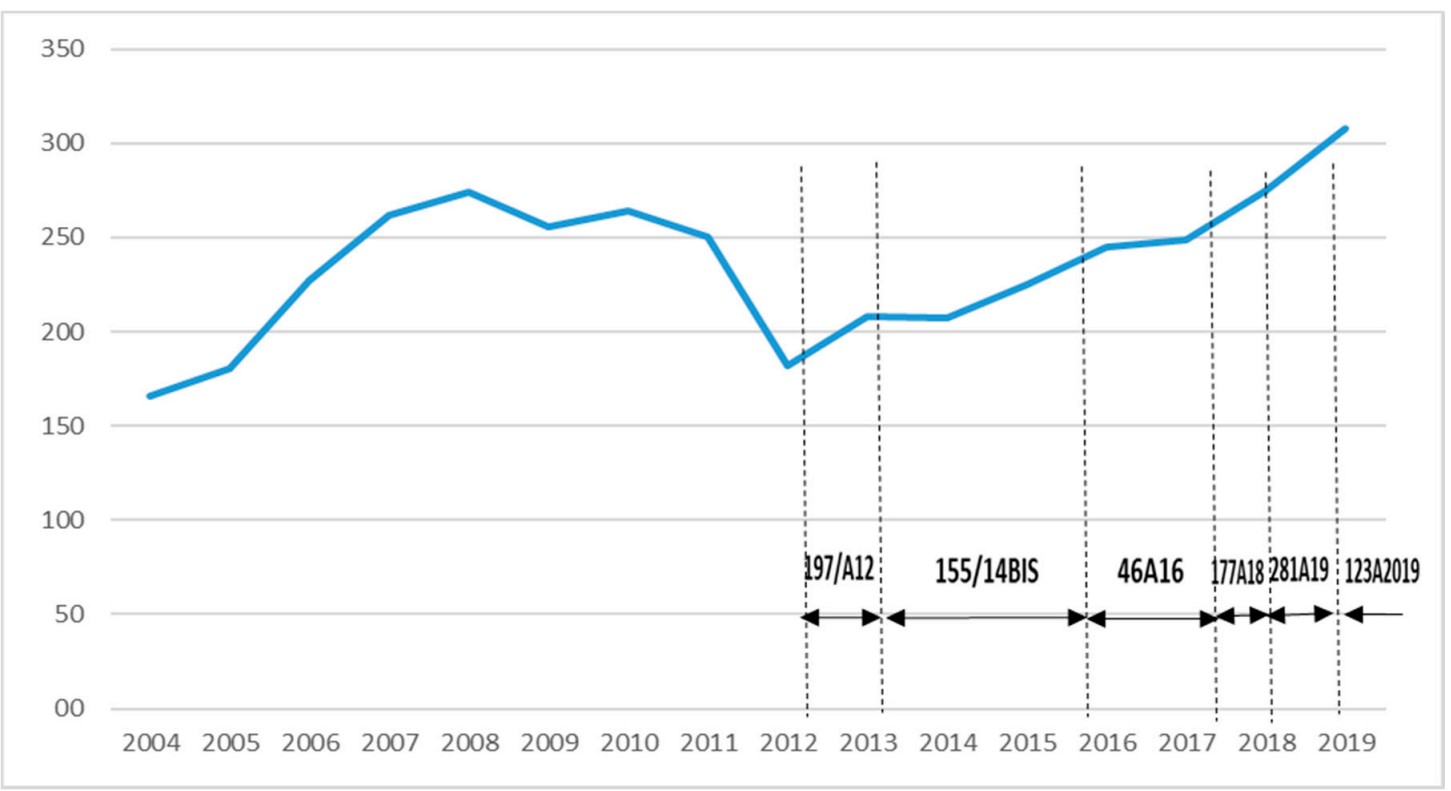

Figure 2. Thousands of passengers carried yearly on the PSO air route ES03 (as of 31 December 2019). Source: Own elaboration based on [21,22]. Explanatory notes: Each arrow denotes a contract period for PSO type 3 with its respective case number for proper identification; where there is no arrow, this denotes a period of activity without any compensation (PSO type 1 or 2), or failing this, under free market conditions. 


\subsection{Considerations on Findings about Public Tenders Relating to PSO Services on Air Route ESO6}

This is a clear case of PSO imposition relating to air services linking two islands within an archipelago, but of substantial differences in population size and territory coverage. As the fastest way to ensure the transportation of people and goods to remote areas, air routes are economic and social drivers for the development of peripheral regions, such as the Canary Islands. On occasion, if airlines incur a loss in profit, they are forced to diverge from such scheduled air services and move towards other regular routes. This was precisely the case of the route LPA-VDE, whose performance did not sufficiently guarantee the existence of adequate means of transport between both islands. This led to an increased risk of the cessation of regular air services on such a route. As can be seen in Figure 3, the evolution of the route required public authorities to design a PSO route (type 3) by launching procurement procedures for contracting air services. Such public intervention has facilitated air services on this route thanks to the corresponding procurement procedures, for a total of EUR 2,932,476, whose budgetary saving, compared with the award amount of the two successful tenders, sums to a total of EUR 12,774. Although the corresponding awarding procedures, such as 108 BIS/A14 and 20/A16, for scheduled air services on route ES06 were not conducted entirely under the digital tendering ecosystem resulting in e-procurement management, the performance on this route has been growing continuously since the beginning of 2013. Another distinctive feature is that it shows high capacity for resilience, since demand for flights on this route has been growing at a scorching pace in spite of long periods of operation without subsidization from the PSO schema. As shown below, for the period between 2013 and 2019, there have been two periods where this PSO route was operated under type 1, and the calculated value of CAGR stands at 20.2\%. Although the last PSO contract (10/A16) expired on 31 July 2018, the route has since been operated without any PSO subsidization provided directly to air carriers. It is also worth pointing out that there was an unsuccessful tender procedure managed under e-procurement (79/A18). Despite that, the growth of demand for flights on the route seems not to have been disrupted. Apparently, the continued resident subsidy has led to the maintenance of good performance belonging to such scheduled air services in regard to the passengers carried.

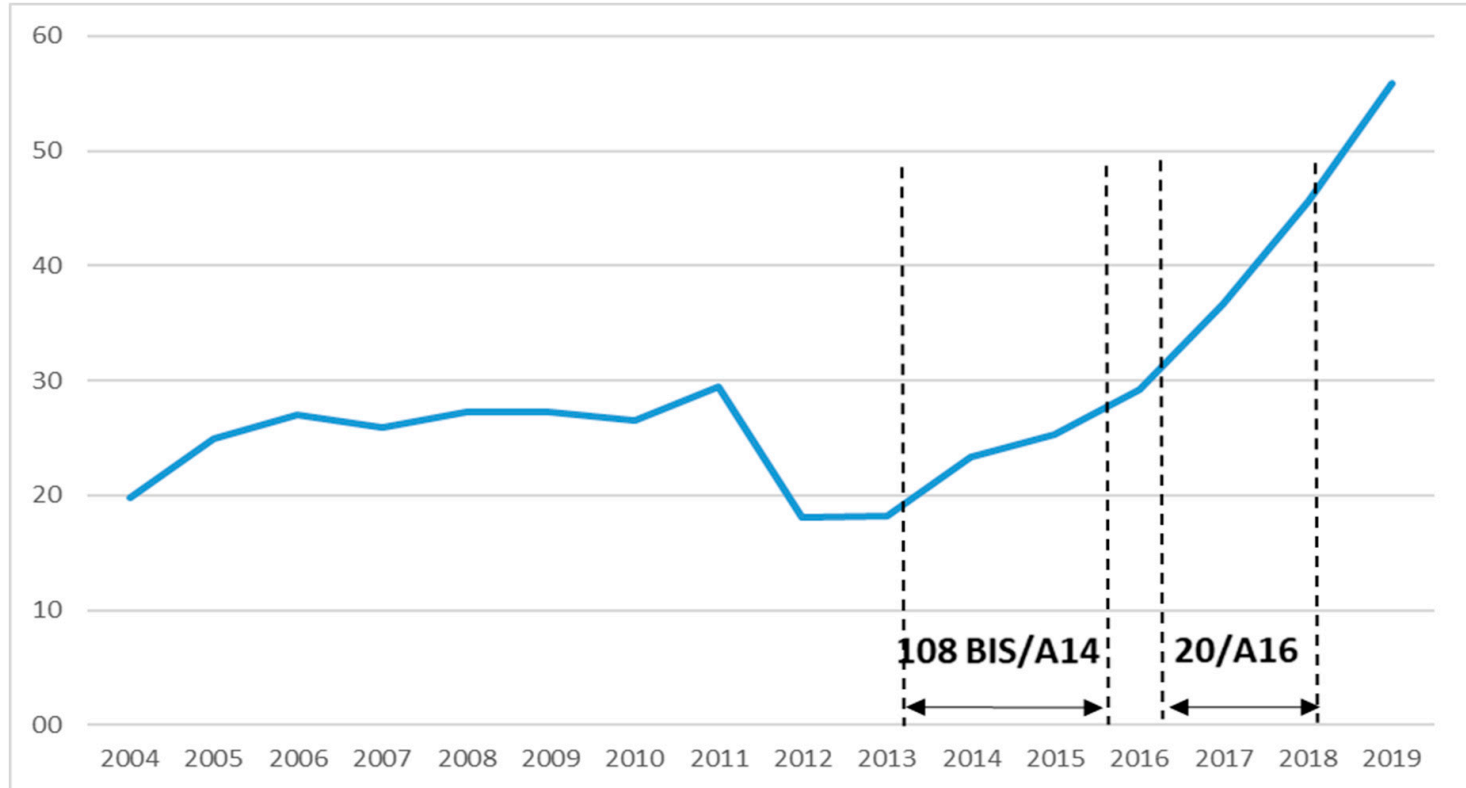

Figure 3. Thousands of passengers carried yearly on the PSO air route ES06 (as of 31 December 2019). Source: Own elaboration based on [21,22]. Explanatory notes: Each arrow denotes a contract period for PSO type 3 with its respective case number for proper identification; where there is no arrow, this denotes a period of activity without any compensation (PSO type 1 or 2), or failing this, under free market conditions. 


\subsection{Considerations on Findings about Public Tenders Relating to PSO Services on Air Route ESO7}

The air route LPA-TFN belongs to the air transport network in the Canary Islands, in addition to directly serving the local populations of the largest islands within the archipelago. Unlike the previous case, the so-named ES06, the air route linking Gran Canaria to Tenerife is a fundamental route for socio-economic development in the region. Such an air route is indispensable to maintaining adequate transport services in this peripheral area. Both the national government and regional authorities have ascribed paramount importance to the evolution of the domestic transportation market in connection with the route performance. As this air route was initially operated in a free market regime and then with a PSO imposition, it is interesting to observe the evolutionary demand for these direct air services in order to compare the different operating periods depending on whether they were subsidized by a PSO contract. In this regard, Figure 4 clearly shows how the curve of passenger traffic was impacted by the Great Recession of 2008, and the effect that PSO imposition had on the route performance. For the period 2004-2019, it appears that public tenders for public contracts on the route led to a tremendous increase in demand for these regular air services, achieving thus a GADR of $1.6 \%$.

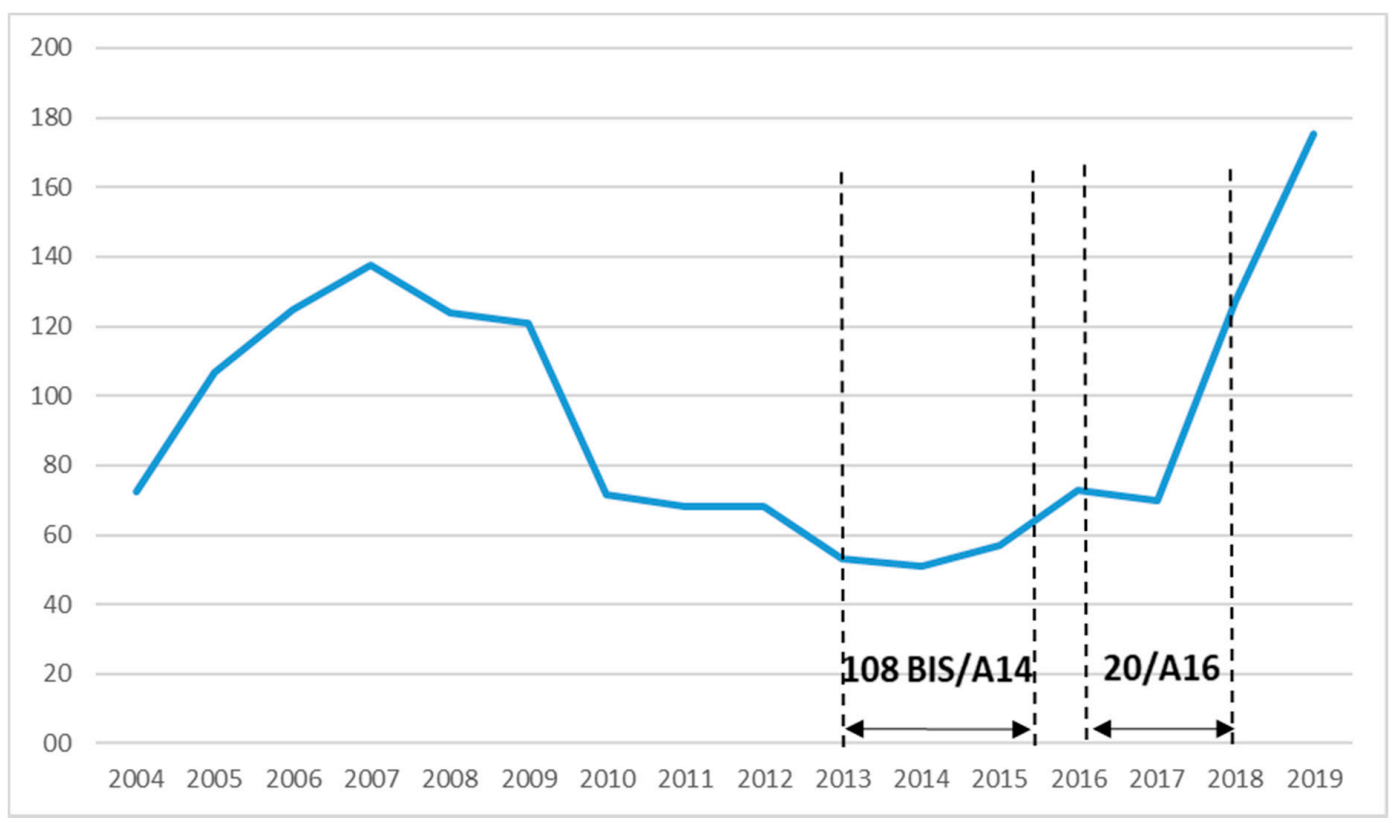

Figure 4. Thousands of passengers carried yearly on the PSO air route ES07 (as of 31 December 2019). Source: Own elaboration based on [21,22]. Explanatory notes: Each arrow denotes a contract period for PSO type 3 with its respective case number for proper identification; where there is no arrow, this denotes a period of activity without any compensation (PSO type 1 or 2), or failing this, under free market conditions.

Although the last contract (20/A16) was not awarded under a full e-procurement system, it also seems that demand has been growing consistently due to resident subsidy. Therefore, there is no need for state aid for the airline operating the route in order to maintain its economic equilibrium. Similarly, this effect has been seen in certain air routes within the Canary archipelago as well, such as route ES06. Consequently, it appears that the termination of a PSO contract for scheduled air services linking both islands does not necessarily entail a sudden drop in demand. Furthermore, direct flights on the route were operated for 40 months and covered two public contracts not linked with each other (respectively, 108 BIS/A14 and 20/16). The resident subsidy seems to be the main cause of the steady growth of this regional route, as such government incentives are exclusively for residents living in the Canary Islands and do not include other Spanish citizens. In view of the results of the research concerning air route ES07, so far, a strong domestic demand for regular air services and the permanent resident subsidy have been sufficient to promote a stimulating leverage. 


\subsection{Considerations on Findings about Public Tenders Relating to PSO Services on Air Route ES12}

Along with the case below, the air route GMZ-LPA belongs to the public transport network of the Canary Islands, whose main purpose is to serve the resident population of La Gomera and thus aims to strengthen the mobility of the local population by imposing a PSO. With the advent of the last world economic crisis (the so-called Great Recession), direct flights on this route suffered from a dramatic loss of passenger traffic to the point at which they were abandoned in early 2009. Since then, this route has remained without continuous direct flights. While the possibility of resuming direct flights between both islands has been broadly discussed both at a local and a regional level, no interested party has submitted any information that would suggest the possibility of operating on air route ES12 again under free market conditions. As soon as direct flights were resumed, the number of passengers carried on the route has been rising at the same level as in 2014. In fact, the CAGR calculated for the period 2004-2019 is $0 \%$. Hence, in that case, it seems that a resident subsidy is not sufficient in itself to stimulate sufficient demand for making direct flights commercially sustainable, but it needs to be supported by tendering PSO contracts if it is applied in supporting direct air services linking both islands.

As seen in Figure 5, the tender process for public air service contracts on both PSO routes serving La Gomera with mainly non-direct flights has led to a slight recovery of passenger traffic for the scheduled air services GMZ-LPA, however on regular air services operated via TFN. Moreover, the budgetary saving from the three procurement procedures (in chronological order, 108 BIS/A14, 20/A16, and 15/A18) has accomplished thus far a total of EUR 288,674 for this route, the third being through an e-procurement procedure (15/A18). Whilst direct flights between both islands have been mainly operated in the summertime, a favorable tendency is observed precisely in the evolution of air passengers carried from July to September 2019. The imposition of a PSO on air route ES12 is a clear example of a public intervention mechanism to ensure an adequate transport mode on ultraperipheral routes, particularly when adequate alternatives are not available. This effect has been seen in other air services as well, such as those related to PSO routes ES21, ES22, and ES23, and seems to explain how the PSO schema, especially under type 3, can help in reactivating scheduled air services in EU developing regions.

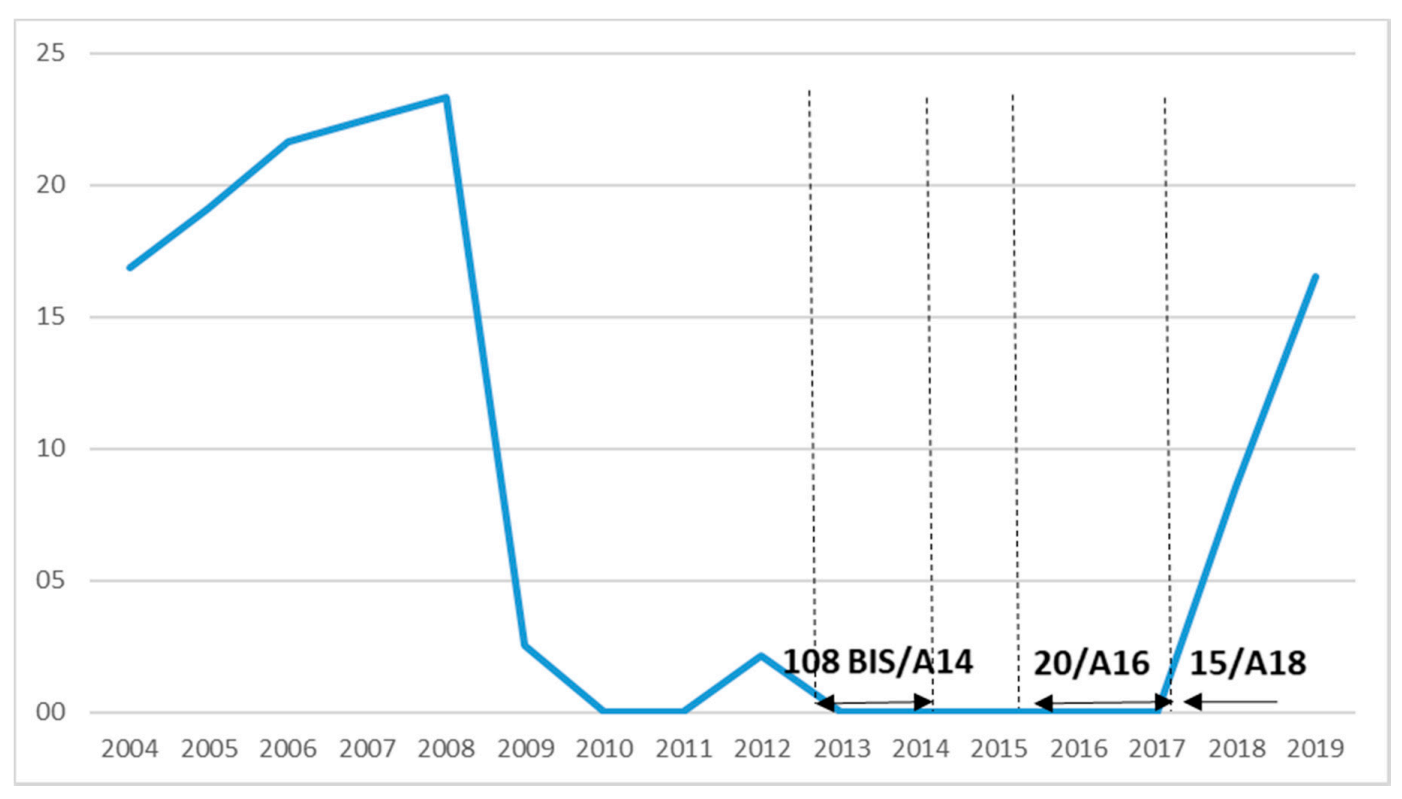

Figure 5. Thousands of passengers carried yearly on the PSO air route ES12 (as of 31 December 2019). Source: Own elaboration based on [21,22]. Explanatory notes: Each arrow denotes a contract period for PSO type 3 with its respective case number for proper identification; where there is no arrow, this denotes a period of activity without any compensation (PSO type 1 or 2), or failing this, under free market conditions. 


\subsection{Considerations on Findings about Public Tenders Relating to PSO Services on Air Route ES13}

Together with the previous case, the route GMZ-TFN is a part of the PSO schema serving the island population living in La Gomera. Unlike the case of ES12, this route has traditionally seen a strong demand even throughout the last worldwide economic downturn, and has recently been awarding public contracts due to the PSO imposition on regular flights. In this regard, the public tenders have aimed to ensure the mobility of people by providing proper monetary compensation to the route operating carrier. The total cost of state aid directly paid to the awarded airline from the three tender processes, one of them carried out as a full e-procurement procedure (15/A18, currently in force) in order to meet the PSO (type 3) requirements, has amounted to EUR 5,522,076. Furthermore, it has recently experienced notable growth due to the demand for these air services on this air route, particularly from the enforced entry of the first PSO contract on 1st August 2014, as seen in Figure 6. Thus, it is interesting to note that demand growth came to a halt within the period between 1 January and 31 July 2016, precisely when there was no PSO contract enforced. Nevertheless, the evolutionary demand for this route seems to be on a path towards sustainable growth. In this context, the GADR calculated over the period analyzed (2004-2019) was 4.1\%. This shows a mutual dependency between the subsidization of scheduled transport services from the imposition of PSO on the air route ES13 and its continuous traffic growth in carrying air passengers. This is further strengthened by the fact that such an administrative imposition has been applied in two steps, one between 2006 and 2011 under a PSO of type 1, and the second since 2011 under a PSO of type 3. Evidence from Figure 6 sheds further light on the significant effects of efficient public tendering procedures on the preservation of scheduled air services, particularly those relating to e-procurement management from the corresponding PSO imposition, such as public contract 15/A18. This has also made public bodies able to open a call for tenders more expeditiously, and therefore allows the concatenation of the new contract (15/A18) with the previous one (20/A16). The number of air passengers on the route has been increasing every year since 2012, and it has been clearly motivated by the fact that public authorities have been supporting possible losses of operating expenses of regular flights through PSO contracts, in addition to a resident subsidy. Indeed, as shown below, growth abruptly stalled in the short timeframe between 108 BIS/A14 and 20/A16 in which there was no PSO contract.

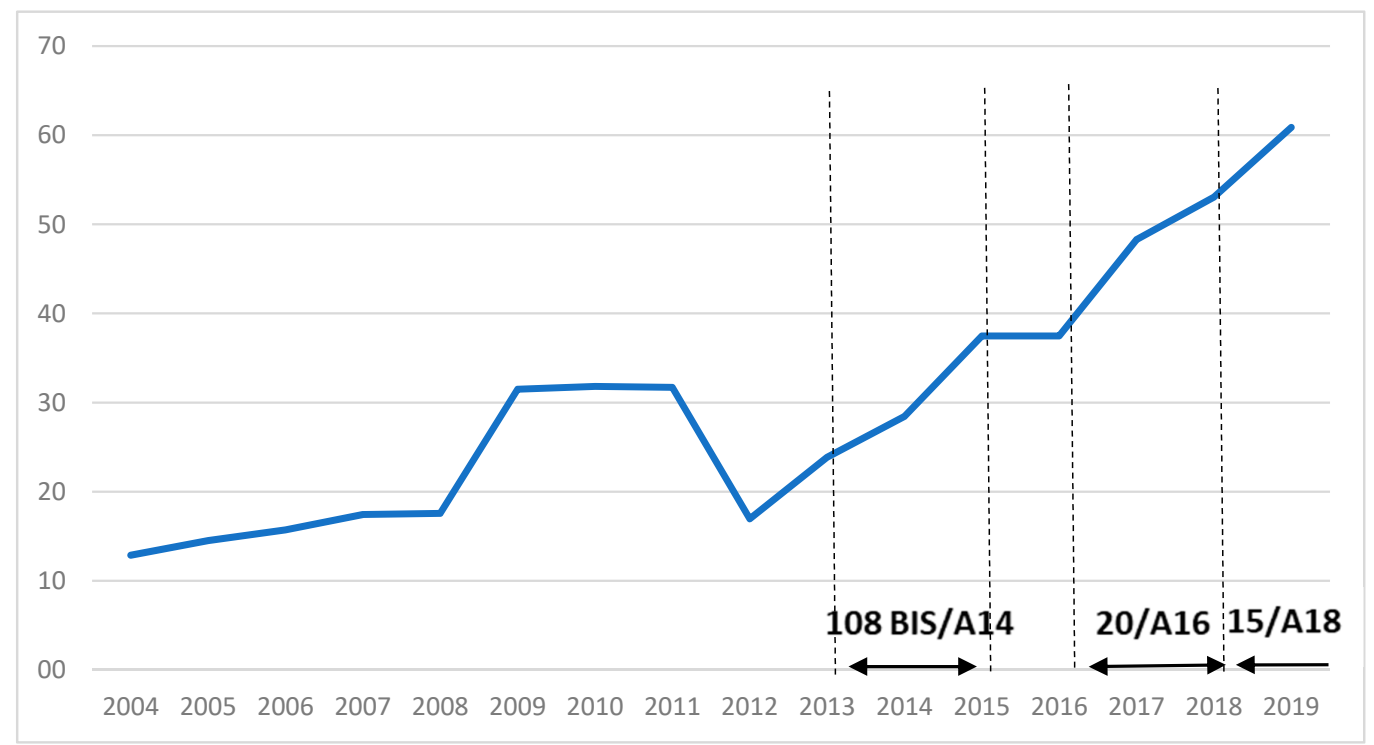

Figure 6. Thousands of passengers carried yearly on the PSO air route ES13 (as of 31 December 2019). Source: Own elaboration based on [21,22]. Explanatory notes: Each arrow denotes a contract period for PSO type 3 with its respective case number for proper identification; where there is no arrow, this denotes a period of activity without any compensation (PSO type 1 or 2), or failing this, under free market conditions. 


\subsection{Considerations on Findings about Public Tenders Relating to PSO Services on Air Route ES19}

The imposition of PSO on scheduled air services serving the region of Extremadura has led to an increased demand for fights from Badajoz airport since the corresponding public contract was awarded by the national government's Ministry of Public Works. Traditionally, such regional airport infrastructure has been underused in operating regular air services for the carriage of passengers, particularly in the case of international flights. However, the existence of the Spanish air force base, located near the civil airport terminal, appears to have had a considerable impact on keeping the entire infrastructure lively and active, despite a significant drop in the number of passengers carried until the summer of 2012. Currently the public air transport network from this airport comprises two routes linking Badajoz to the two largest Spanish cities, Barcelona and Madrid. Although the route BJZ-MAD was operated under free market conditions, none of the airlines operating this route were able to make these air services profitable or reliable, which resulted in both UX and YW ceasing their operations at Badajoz. In view of the sudden lack of supply of these flights, the route was converted into a PSO route under type 3, and therefore an e-procurement procedure was carried out for the tendering of a service contract (123/A18), which remains currently in force since 28 October 2018. Thanks to diligence and flexibility in the resolution of an e-procurement procedure related to awarding the tender for this PSO case, as seen in Figure 7, there has been a significant increase in the number of passengers carried on this route. All of this has led to the CAGR of $0.14 \%$ within the period between 2004 and 2019, in addition to a budgetary saving of EUR 1,750,000 from the e-procurement process for the contract 123/A18.

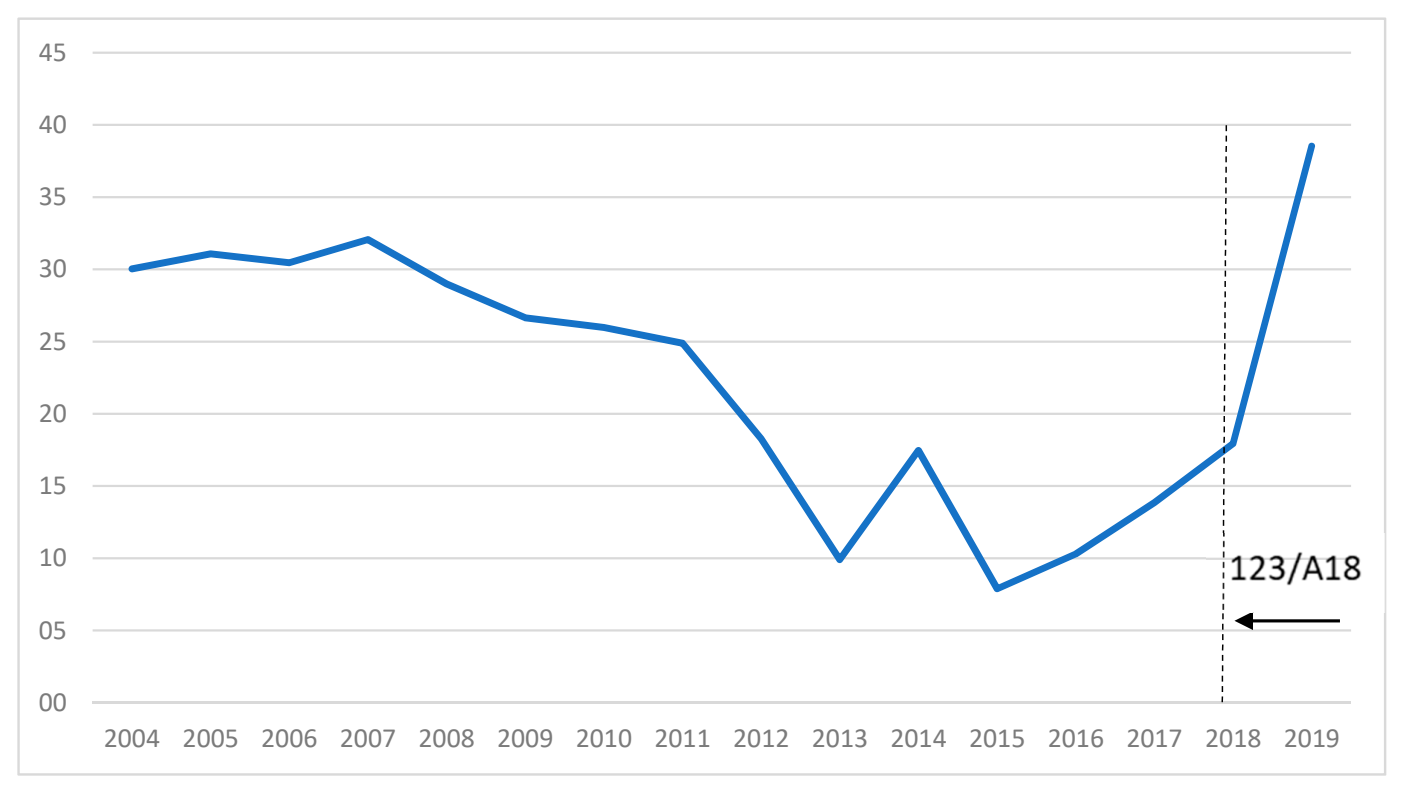

Figure 7. Thousands of passengers carried yearly on the PSO air route ES19 (as of 31 December 2019). Source: Own elaboration based on [21,22]. Explanatory notes: Each arrow denotes a contract period for PSO type 3 with its respective case number for proper identification; where there is no arrow, this denotes a period of activity without any compensation (PSO type 1 or 2 ), or failing this, under free market conditions.

Other findings indicate that the subsidies from PSO imposition appear to have increased the demand for regular flights to and from Badajoz than marketed tourism promotions. This explains the slight upturn in demand between mid-2012 and mid-2017 due to two public marketing contracts, which initially encompassed two periods (from July 2012 to July 2014, and then from August 2015 to March 2017), and were budgeted at EUR 1,800,000 and EUR 1,480,000, respectively. Nevertheless, as seen in the graph below, the growth performance of demand has been much better from subsidization under PSO contracts. It is clear that the imposition of a PSO on such route supported by a public contract causes a stimulating effect on the demand for flights. 


\subsection{Considerations on Findings about Public Tenders Relating to PSO Services on Air Route ES2O}

The route ES20, together with the previous one, is a part of the regular air services imposed by the Spanish authorities on peripheral areas, such as Extremadura. The route linking Badajoz to Barcelona, the second largest city in Spain, has traditionally been the subject of special interest from the regional government (Junta de Extremadura), since adequate public transport services can contribute to the further development of the regional economy. The imposition of a PSO on regular air services from Badajoz has thus given an opportunity to contribute to the strengthening of this airport in operating domestic flights. Being the only commercial airport in the region, its catchment area extends far beyond the regional territory of Extremadura, including the neighboring areas of Portugal. Due to the existence of large number of family ties among the population living in Catalonia and Extremadura, the need for transportation to link both Spanish regions has traditionally been constant over time. However, over the last few years, the route has undergone marked changes in respect to the demand for air services, which seems to be a response to the specific conditions of the region, which is an addition to previous marketing contracts promoting regional tourism.

As previously mentioned, related marketing contracts were awarded by the regional government in order to stimulate the establishment of new flights to and from Badajoz airport, thus promoting tourism in the region. As soon as these marketing contracts were terminated in June 2014 and March 2017, respectively, the route's activity dropped significantly. As is evident from Figure 8, the intensity of demand is represented as an erratic path due to its heavy reliance on economic support from public contracts. Since air routes operating within Spanish mainland are not subject to a resident subsidy, the only way to promote adequate scheduled air services is to impose a PSO on such routes, specifically under type 3, and then to award a public contract for establishing regular flights. In sum, this is a typical example of an air route in the public interest that needs to be encouraged and supported, if there exists no rapid alternative to road and train transport for passengers. Nevertheless, the PSO contract (123/A18) currently in force was carried out as a result of an e-procurement procedure, which has led to a $25 \%$ increase in savings with respect to the amount initially budgeted for awarding these air services.

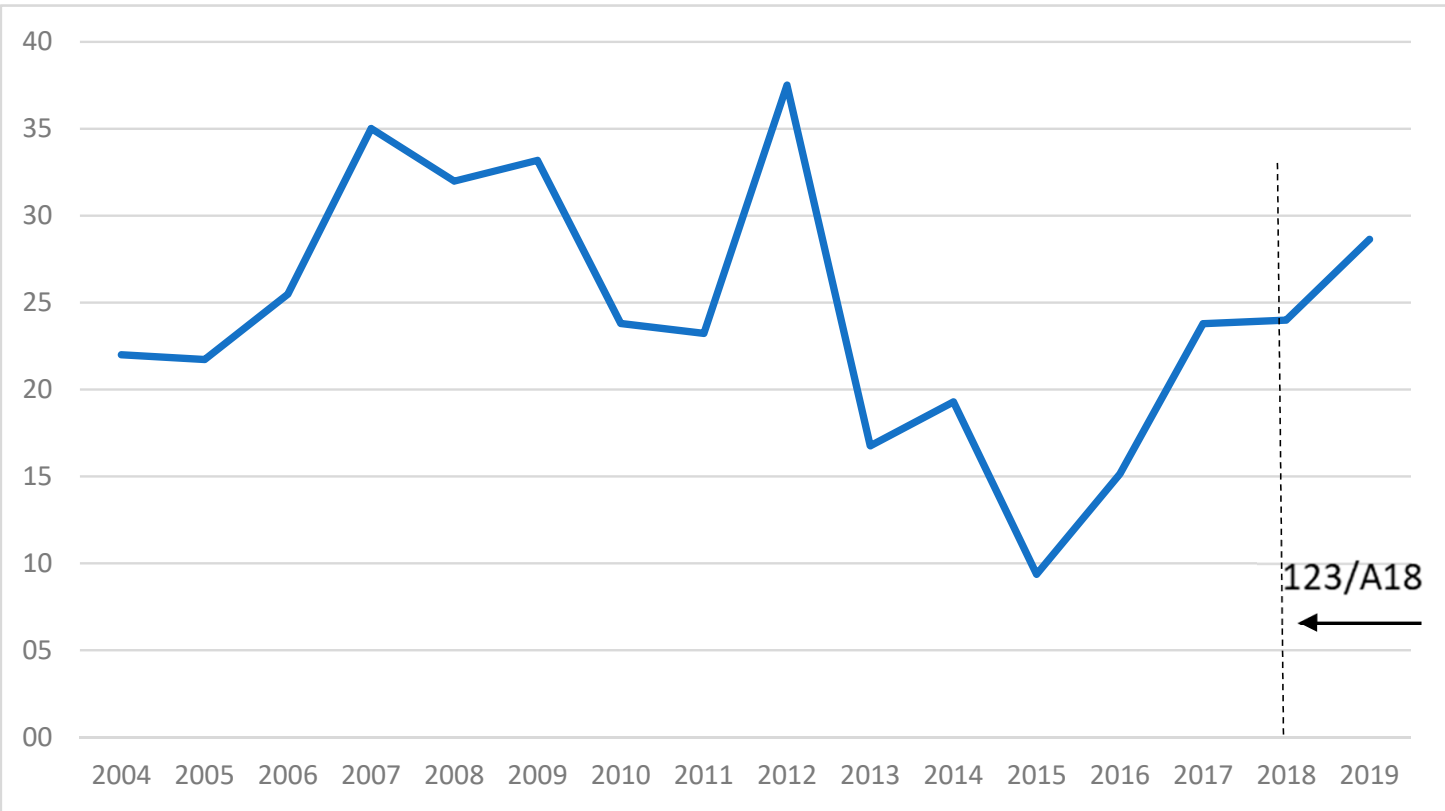

Figure 8. Thousands of passengers carried yearly on the PSO air route ES20 (as of 31 December 2019). Source: Own elaboration based on [21,22]. Explanatory notes: Each arrow denotes a contract period for PSO type 3 with its respective case number for proper identification; where there is no arrow, this denotes a period of activity without any compensation (PSO type 1 or 2), or failing this, under free market conditions. 


\subsection{Considerations on Findings about Public Tenders Relating to PSO Services on Air Route ES21}

This air route MLN-LEI is a part of the PSO network broadly based in the city of Melilla, an autonomous city under Spanish sovereignty, whose objective is to serve the local population in addition to those living within a large catchment area located in the northeastern region of Morocco. Historically, this air corridor has had a greater economic component, being strongly linked with trade relations between Melilla and mainland Spain. Moreover, Almeria being the nearest gateway from Africa to trans-European road networks, scheduled air services on the route have played a vital role in enhancing connectivity among people living on both sides of the Mediterranean Sea, particularly for those visiting their relatives in the summertime. Although this route has reaped the benefit of the Spanish resident subsidy (formerly 50\%, currently 75\%) for those living in Melilla, the number of air passengers has been dropping steadily since 2004. Nevertheless, upon the 328A19 public contract award, the imposition of a PSO has led to a revival of flight demand. As can be seen in Figure 9, this seems to be growing substantially again.

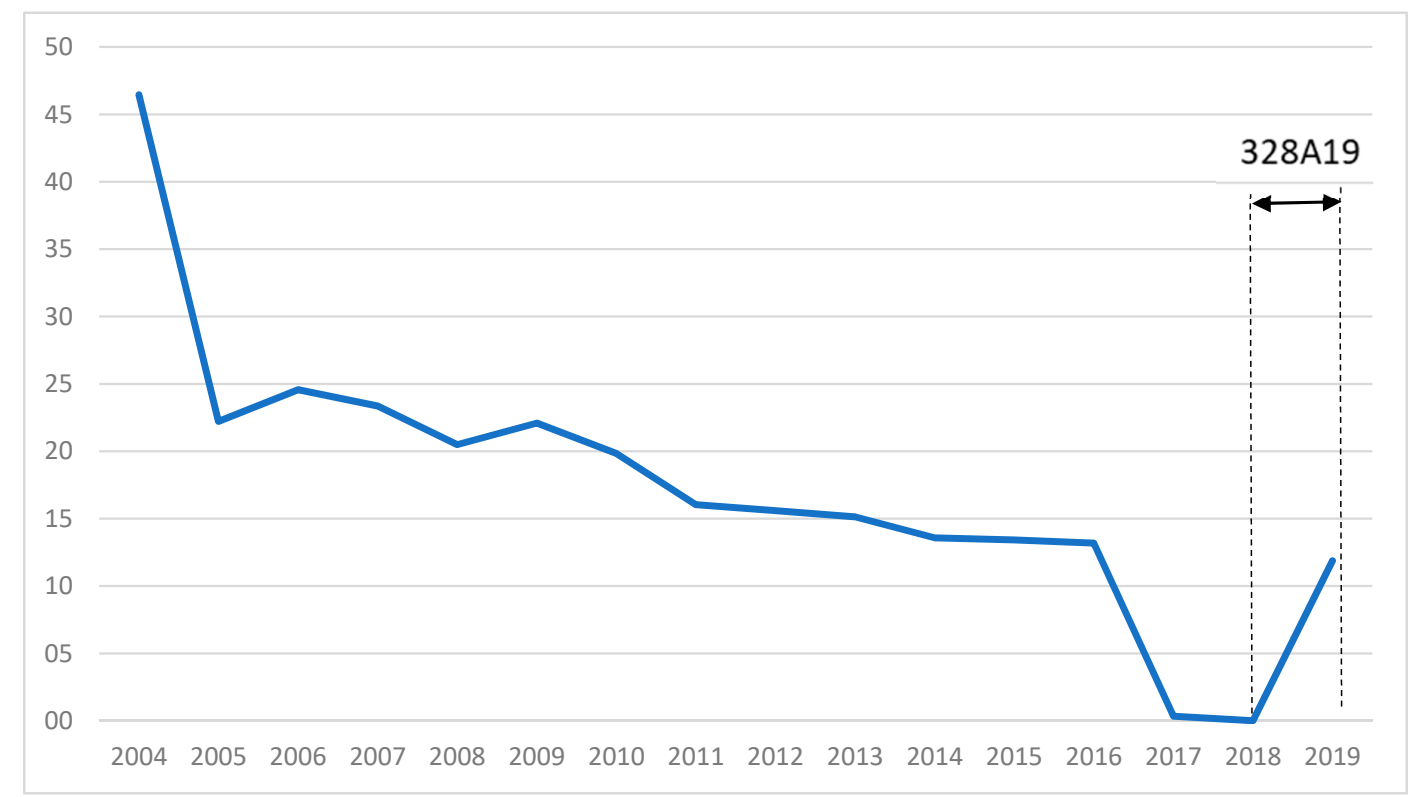

Figure 9. Thousands of passengers carried yearly on the PSO air route ES21 (as of 31 December 2019). Source: Own elaboration based on [21,22]. Explanatory notes: Each arrow denotes a contract period for PSO type 3 with case number concerned; the area without an arrow denotes a period of activity without any economic compensation (type 1 or 2), or failing this, under free market conditions; the case 162A2020 has not been mentioned on the graph because this is an ongoing contract since 1 January 2020.

In designing public air services for such an isolated city, along with understanding the transportation needs of the beneficiaries, it has also been important to take into consideration certain restrictions associated with the airport, such as aeronautical limitation surfaces, as well as take-off and approach paths, and runway length. Therefore, this fact has limited air operation, and thus forced airlines to use turboprop aircraft in operating any regular air services from this airport. These technicalities constitute a constraint for the aviation market, thus reducing the number of potential air carriers interested in serving this route. Consequently, a specific aircraft type, specifically a turboprop (e.g., ATR 72-600 or the DASH 8-400 series) capable of operating in Melilla airport (MLN), had to be clearly specified in the documents relating to competitive tendering for PSO contracts, including the imposition of operating requirements, in addition to other requirements such as daily flights or maximum fares. All this has led to the existence of an air carrier interested in bidding for the corresponding PSO contract (328A19). Additionally, thanks to an e-procurement procedure for tendering this public contract, there was a saving of $27.7 \%$ in respect of the initial budget. 


\subsection{Considerations on Findings about Public Tenders Relating to PSO Services on Air Route ES22}

As in the previous case, the evolution of passenger numbers carried on the route MLN-GRX shows certain noteworthy aspects relating to its performance with regard to the annual passenger volume. After the eruption of the Great Recession in 2008, particularly after its acceleration in 2010 within the Eurozone, air passenger traffic on this air route dropped massively by over $50 \%$ between the years 2007 and 2014, as can be seen from Figure 10. The airline (YW) operating this regular air service was forced to leave this route in early 2017 due to its low occupancy. In view of the need to keep operating such a vital link for both cities, the Spanish Ministry of Public Works had no other option but to impose a PSO under type 3 on this route, and then to set an e-procurement procedure to efficiently award the contract, named 328A19, for the required air services. Thanks to the public contract, regular flights on the route were reactivated, and thus have been operating successfully since May 2019. On the basis of the information revealed in Figure 10, it is clear that the combined effect of the compensation to the awarding airline (YW) resulting from the existence of a resident subsidy (see Annex I of Royal Decree 1316/2001 of 30 November) has led to an increased number of passengers carried on this route, in addition to a budgetary saving of EUR 893,866 from the PSO contract awarded for the period between 1 May 2019 and 31 December 2019. Clearly, the imposition of a PSO for such air services has not only revived air traffic on this route, which had been cut by the airline (YW) formerly operating regular flights, but has also led recently to a fast rise in the number of passengers carried. In fact, the calculated value of CAGR is $0.6 \%$ for the period 2013-2019, whereas for the period 2004-2019 it was 0.3\%. Furthermore, as usual for air routes revitalized by imposing PSOs, in addition to being subsidized, there was only one bidder so far, precisely the sole airline operating formerly the route in the free market regime. This seems to indicate that previous experience in operating regular air services on certain regional routes may be a competitive factor in bidding for PSO contracts, particularly if the airline uses an efficient fleet that can be easily adapted to meet PSO requirements. In the particular case of air route ES22, as previously mentioned, air services have been operated with a turboprop aircraft as the only viable option in flying efficiently to and from Melilla airport.

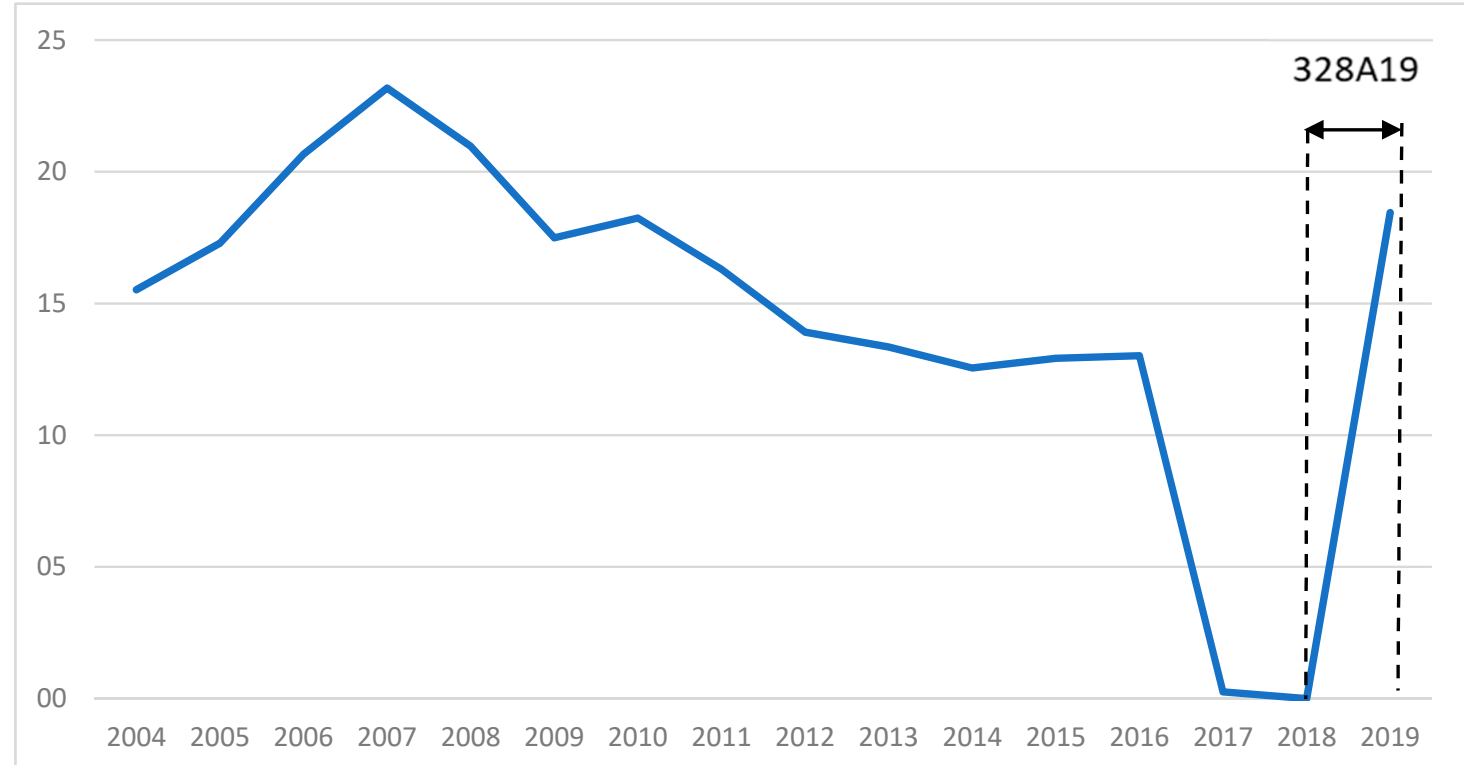

Figure 10. Thousands of passengers carried yearly on the PSO air route ES22 (as of 31 December 2019). Source: Own elaboration based on [21,22]. Explanatory notes: Each arrow denotes a contract period for PSO type 3 with case number concerned; the area without an arrow denotes a period of activity without any economic compensation (type 1 or 2), or failing this, under free market conditions; the case 162A2020 has not been mentioned on the graph because this is an ongoing contract since 1 January 2020. 


\subsection{Considerations on Findings about Public Tenders Relating to PSO Services on Air Route ES23}

Although being part of the imposition of a PSO on routes serving Melilla (MLN), the route linking to Sevilla (SVQ) differs significantly from those linking to Almeria and Granada. Whilst being a form of public transportation with no possible direct alternatives, the PSO imposed on air route MLN-SVQ appears to be a low-demand service, as can be noted from Figure 11. In contrast to the two previous cases, route ES23 had not been previously operated in a regular and continuous manner. It has not been shown that there was latent demand for the scheduled air transport of either passengers or goods in previous years. Nonetheless, local authorities saw the opportunity to strengthen the supply of direct flights to and from Melilla airport, mainly those linking to the regions with the most extensive economic ties to the area within Spain, in particular, Andalusia. Hence, this PSO route was established, together with two other routes (ES21 and ES22), under a single tender (A328/A19), in order to be more appealing to bidders so that it could be awarded promptly, and thus preventing the declaration of an unsuccessful procedure. In order to avoid a lack of bidders on public tenders for PSO air services, as was the case with air route ES13 in regard to procedure 209A19, the procurement of scheduled flights operating in Melilla opened the invitation to tender for three routes under a single awarded air carrier. As e-procurement procedures usually enable synergies at many levels, this tender procedure made possible a saving on the initial budget for air route MLN-SVQ of up to EUR 893,866. However, the current active demand for this air transport service is still relatively weak. According to our calculations, in the period from 2004 to 2019, this route had one of the poorest performances (CAGR of $-0.2 \%$ ) across the PSO schema of air routes in Spain, in addition to the lowest volume of passengers carried (22.2k). Nevertheless, the tender process (328A19) for the first PSO contract on this route was carried out based on an e-procurement procedure that led to significant stimulation of the demand for these regular air transport services. Significantly, as in the cases of other PSO air routes operating to and from Melilla airport, the stimulation of any public subsidization from both the PSO contract and a resident subsidy, in addition to former agreements for tourism promotion at a local level, seem to be key factors in this growing demand.

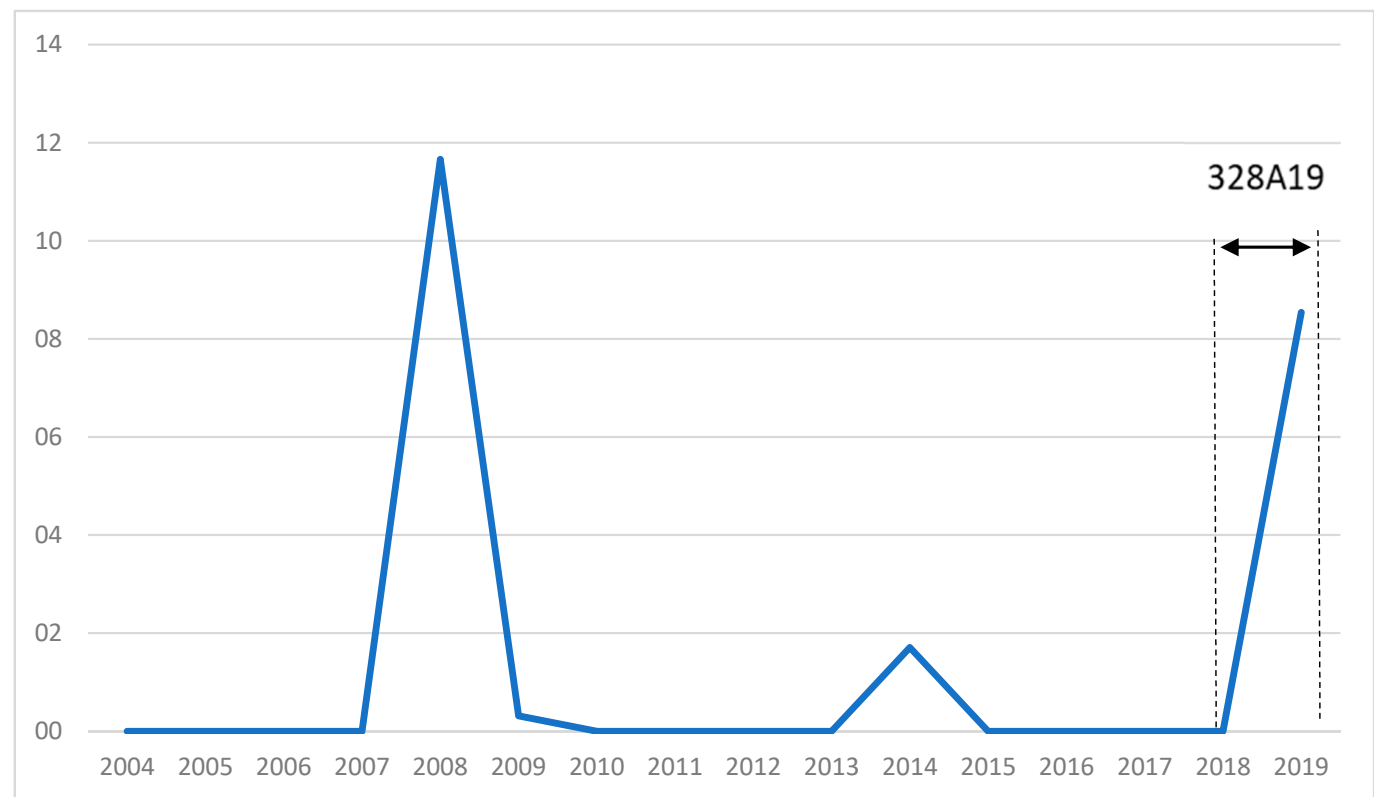

Figure 11. Thousands of passengers carried yearly on the PSO air route ES23 (as of 31 December 2019). Source: Own elaboration based on [21,22]. Explanatory notes: Each arrow denotes a contract period for PSO type 3 with case number concerned; the area without an arrow denotes a period of activity without any economic compensation (type 1 or 2), or failing this, under free market conditions; the case 162A2020 has not been mentioned on the graph because this is an ongoing contract since 1 January 2020. 


\section{Conclusions}

Throughout this paper, a whole new outlook has been given on the PSO schema applied to the Spanish case, especially issues related to procurement procedures with regards to inviting tenders and awarding the concession of public air services. Thus, the main objective of this research was to examine not only how impositions of PSO on routes can ensure adequate air services, but also whether the use of e-procurement procedures leads to increased efficiency on the public tender side. These challenges have been reflected in the considerations selected for this study, in particular those analyzed for each PSO route under type 3. Hence, a total of eleven PSO routes imposed in Spain so far have been subsidized under the Air Services Regulation 1008/2008 by awarding concessions for scheduled air services on routes restricted to one carrier. As this form of public intervention on the aviation market generates a strong distortion of free competition in the EU internal market, the competent civil aviation authorities should be extremely careful in imposing PSO routes, particularly those under type 3. Thus, in the case of Spain, the national government has avoided the indiscriminate use of this public intervention, paying particular attention to setting a restriction to one carrier, and therefore to launching a procurement procedure to award the corresponding compensation. However, the reality of the current air transport market points towards a concentration of air carriers, and therefore a reduction in the number of market players. This will lead to a small number of airlines interested in participating in tendering procedures from PSO impositions. Consequently, there will be an increase in the amount of economic compensations as more bidders can meet the requirements for air services concerned. The present paper has revealed PSO impositions whose tender process was declared null or void (108/A14, 155/A14, 79/A18, 209A19), and even whose awarded carrier terminated the public service earlier than the date signed on the contract (197/A12). Unfortunately, while the implementation of e-procurement seems to lead to more efficient and agile procedures, the ratio of unsuccessful tender processes remains quite high with respect to total procurement procedures carried out so far. In fact, our findings suggest the necessity of encouraging improvement opportunities in order to avoid distortions of the EU transportation market when unnecessary public services are imposed on regular air routes with compensation. This is precisely the most restrictive type of the current PSO schema. Further related questions dealing with air market issues have also been widely discussed in this paper. For instance, from a cost perspective, e-procurement can lead to a risk relating to maximizing the range of realized performance on the bidder's side [27]; from an innovation perspective, public procurements can contribute to the creation of markets for new transport services [28]; and from a competitiveness perspective, the PSO schema can affect the economic performance of air carriers, particularly in the case of regional airlines [29].

As seen previously, the PSO schema has been imposed on twenty-three Spanish air routes to date, and of these, eleven were involved in awarding public contracts to provide scheduled passenger air transport services. Since May 2018, related calls for tenders have been conducted under a full e-procurement process from the unified platform at national level, the so-called PLACSP, the earliest being the case numbered 15/A18 concerning routes ES12 and ES13. Having carefully examined the corresponding administrative procedures for tendering scheduled air services on these eleven routes, a common characteristic of the PSO system results from the analysis of passenger traffic for the period 2004-2019. Clearly, the imposition of a PSO under type 3 has a stimulating effect on the demand for regular air services. Equally clear is the fact that such a positive effect can be amplified when there is a resident subsidy on those PSO routes serving peripheral areas and remote territories. A similar effect can be observed on certain PSO air services operated under type 1 or 2 , where the passengers concerned can be eligible for a resident discount. This seems to suggest that in very specific cases, such as route ES07, the resident subsidy would be enough to ensure the continuity of air transportation. However, airlines operating such routes may be tempted to raise air fares, while knowing that the reduction of standard air fares has recently improved by up to $75 \%$. In this regard, it is highly desirable that future modifications of Air Services Regulation 1008/2008 strengthen the oversight function necessary for the 
residency subsidy in order to avoid distortions of the EU transportation market when an unnecessary $\mathrm{PSO}$ is imposed on a regular route with compensation.

\section{Future Research Directions and Limitations}

This section intends to provide interested readers with a few ideas on how to gain a source of inspiration for their future research on issues related to transportation in terms of efficiency and sustainability. As previously pointed out, this paper aims to thoroughly study the effect of PSO impositions on the air transport market in Spain by shedding some light on the details of what should be further done by the public authorities in order to achieve better results than those that have been obtained in procurement procedures, to be specific. As mentioned before, a new research direction can emerge from studies of other domestic air transport markets across the EU where air routes have been declared to be public services (see Table 1). Moreover, the analysis of the market and institutional barriers that hinder open competition in the air transport market can lead to other research topics where more studies might be needed. In this context, further issues can be addressed by examining whether the liberalization of air transport has led to increased competition [30]. Economic issues surrounding air market challenges can also be addressed in future work, such as those related to entrepreneurship in operating PSO air routes [1], in addition to the implications for tourism of promoting private initiatives [31]. Another aspect to take into consideration in future studies on the air market impact of PSO routes is the relationship between connectivity and scheduled air services through hub centrality metrics, as earlier studies suggested [32]. Similarly, the sociopolitical framework of the criteria for justifying the necessary imposition of a PSO on the air routes concerned can be considered as a priority research topic in order to deepen the analysis of the challenges faced by the public transportation system. It may be convenient to gather and analyze evidence on the need for updating the EU legislation applicable to the air market with a special focus on the efficiency and effectiveness of the PSO schema. In this context, earlier works may also be helpful in identifying key aspects for future research involving the review of policies concerned, such as those relating to air connectivity in remote regions worldwide [33] and to multi-level governance from various scales of jurisdiction [34].

The coronavirus disease 2019, also named COVID-19, is causing awful effects on the air market in the passenger transport sector worldwide and is particularly intense for those air carriers operating mostly on long-haul flights due to travel restrictions for public health reasons. Since the most dramatic fall in air activity is occurring principally in both Asia and Europe, many airlines have massively withdrawn international routes, and have then been forced to reduce their fleets. Among other mobility problems arising from preventive health measures against the current pandemic, European airlines have been suffering a severe loss of liquidity because of the strong drop in income, primarily that from ticket sales and ancillary revenues, but also due to ticket refunds for flight cancellations during the pandemic, according to EU law on air passenger rights. Since Regulation (EC) no. 261/2004 is highly beneficial for individuals using air transport services, such an unprecedented situation is leading airlines into different survival scenarios in order to safeguard their liquid assets. As a follow-up to this paper, the related effects on airlines serving PSO routes can be discussed.

On the limitations of this study, it must be pointed out that there are few reliable data on air route performance, such as passenger load factor (PLF) or available seat kilometers (ASK), which can be consulted through free public access. As it is crucial to have reliable data available before carrying out a research project, it took a lot of work to obtain the proper data and then to calculate the results that have been revealed in this paper. Unfortunately, with the exception of the airline headquartered at Gran Canaria airport (LPA), named Binter (NT), it was not possible to find domestic airlines that were willing to collaborate on this research. Most airlines were not able to provide the authors with the required information, and therefore this led to problems investigating the research topic. Nevertheless, the in-depth knowledge that the researchers have of the transportation sector has led us to acquire valuable information for this study, in addition to the invaluable collaboration of competent staff 
members at both national and regional level. As reflected in the comments above, the results revealed by the present study can serve as fundamental information, allowing other researchers to learn about what the transportation market expects of the PSO schema and what challenges relate to this form of public intervention.

Author Contributions: Investigation, A.M.R. and V.M.G.-S. Both authors have read and agreed to the published version of the manuscript.

Funding: This research received no external funding.

Acknowledgments: The authors would like to thank all those who have contributed in providing data at the level of detail necessary to carry out this study. A special mention is attributed to the cooperation demonstrated by public bodies and related authorities at the Spanish national level, such as Aena SME S.A. and Dirección General de Aviación Civil, and others at regional level, such as Consejería de Distritos, Juventud, Participación Ciudadana, Familia y Menor de la Ciudad Autónoma de Melilla, Dirección General de Transporte Marítimo y Aéreo del Gobierno de las Islas Baleares, Consejería de Movilidad, Transporte y Vivienda de la Junta de Extremadura, and Consejería de Fomento, Infraestructuras y Ordenación del Territorio de la Junta de Andalucía, as well as the Directorate-General for Mobility and Transport (DG MOVE) of the EU Commission. Sincere thanks also go to the only air carrier, Binter Canarias S.A., that agreed to collaborate with this research by providing significant information. Finally, the authors appreciate the anonymous reviewers for their thoughtful comments and constructive suggestions on an earlier version of the manuscript.

Conflicts of Interest: The authors declare no conflict of interest

\section{Appendix A}

Airlines named in the paper: Air Berlin (formerly AB), Air Europa (UX), Air Nostrum (YW), Binter (NT), Canaryfly (PM), Iberia (IB), Iberia Express (I2), Ryanair (FR), Spanair (formerly JK), Vueling (VY). Airports named in the paper: Adolfo Suárez Madrid-Barajas (MAD), Almería (LEI), Badajoz (BJZ), El Hierro (VDE), Fuerteventura (FUE), Gran Canaria (LPA), F.G.L. Granada-Jaén (GRX), Ibiza (IBZ), Josep Tarradellas Barcelona-El Prat (BCN), La Gomera (GMZ), La Palma (SPC), Lanzarote (ACE), London City (LCY), Málaga-Costa del Sol (AGP), Melilla (MLN), Menorca (MAH), Palma de Mallorca (PMI), Sevilla (SVQ), Tenerife Norte (TFN), Tenerife Sur (TFS), Vilnius (VNO).

\section{References}

1. Martínez Raya, A.; González-Sánchez, V.M. Some Considerations about Value Creation in Regard to Entrepreneurship and Innovation from Public Service Obligations on Scheduled Air Transport. In Analyzing the Relationship between Innovation, Value Creation, and Entrepreneurship, 1st ed.; Galindo-Martín, M., Mendez-Picazo, M., Castaño-Martínez, M., Eds.; IGI Global: Hershey, PA, USA, 2020; pp. 289-306. [CrossRef]

2. Reynolds-Reighan, A. European Air Transport Public Service Obligations: A Periodic Review. Fisc. Stud. 1995, 58. [CrossRef]

3. Kociubinski, J. Between Lifeline Services and Transport of Convenience-The Model of Public Service Obligation in Air Transport. Eur. Netw. Law Regul. Q. (ENRL) 2014, 2, 232-243.

4. Department for Mobility and Transport (DG MOVE). Public Service Obligations. Available online: https: //ec.europa.eu/transport/modes/air/internal-market/pso_en (accessed on 31 January 2020).

5. Bråthen, S.; Eriksen, K. Regional aviation and the PSO system-Level of Service and social efficiency. J. Air Transp. Manag. 2018, 69, 248-256. [CrossRef]

6. Pita, J.P.; Antunes, A.; Adler, N. Socially-oriented flight scheduling and fleet assignment model with an application to Norway. Transp. Res. Part B Methodol. 2014, 61, 17-32. [CrossRef]

7. Laurino, A.; Beria, P.; Debernardi, A.; Ferrara, E. Accessibility to Italian remote regions: Comparison among different transport alternatives. Transp. Policy 2019, 83, 127-138. [CrossRef]

8. Antunes, A.; Santos, M.; Pita, J.; Menezes, A. Study on the evolution of the air transport network of the Azores. Transp. Res. Part A 2018, 118, 837-851. [CrossRef]

9. Commission Notice. Interpretative guidelines on Regulation (EC) No 1008/2008 of the European Parliament and of the Council. Public Service Obligations (PSO). Off. J. Eur. Union 2017, C 194/01. 52017XC0617 (01).

10. Bråthen, S.; Halpern, N. Air transport service provision and management strategies to improve the economic benefits for remote regions. Res. Transp. Bus. Manag. 2012, 4, 3-12. [CrossRef] 
11. Williams, G.; Pagliari, R. A comparative analysis of the application and use of public service obligations in air transport within the EU. Transp. Policy 2004, 11, 55-66. [CrossRef]

12. Merkert, R.; O'Fee, B. Managerial perceptions of incentives for and barriers to competing for regional PSO air service contracts. Transp. Policy 2016, 47, 22-33. [CrossRef]

13. Abreu, J.; Fageda, X.; Jiménez, J.L. An empirical evaluation of changes in Public Service Obligations in Spain. J. Air Transp. Manag. 2018, 67,1-10. [CrossRef]

14. Pita, J.P.; Antunes, A.P.; Barnhart, C.; De Menezes, A.G. Setting public service obligations in low-demand air transportation networks: Application to the Azores. Transp. Res. Part A 2013, 54, 35-48. [CrossRef]

15. Di Francesco, A.; Pagliari, R. The potential impact of removing public service obligation regulations on air fares between the Italian Mainland and the island of Sardinia. J. Transp. Geogr. 2012, 24, 332-339. [CrossRef]

16. Vega, A.; Reynolds-Feighan, A. The impact of the great recession on Irish air travel: An intermodal accessibility analysis. J. Air Transp. Manag. 2016, 51, 1-18. [CrossRef]

17. Calzada, J.; Fageda, X. Discounts and Public Service Obligations in the Airline Market: Lessons from Spain. Rev. Ind. Organ. 2010, 40, 291-312. [CrossRef]

18. Suau-Sanchez, P.; Burghouwt, G. The geography of the Spanish airport system: Spatial concentration and deconcentration patterns in seat capacity distribution, 2001-2008. J. Transp. Geogr. 2011, 19, $244-254$. [CrossRef]

19. Dimitriou, D.; Sartzetaki, M. Assessing air transport socio-economic footprint. Int. J. Transp. Sci. Technol. 2018, 7, 283-290. [CrossRef]

20. Calzada, J.; Fageda, X. Competition and public service obligations in European aviation markets. Transp. Res. Part A 2014, 70, 104-116. [CrossRef]

21. AENA. Air Transport Statistics in 2004-2019. Available online: www.aena.es (accessed on 31 January 2020).

22. Plataforma de Contratación del Sector Público (PLACSP). Tender History in 2004-2020. Available online: https://contrataciondelestado.es (accessed on 31 January 2020).

23. Merkert, R.; Williams, G. Determinants of European PSO airline efficiency-Evidence from a semi-parametric approach. J. Air Transp. Manag. 2013, 29, 11-16. [CrossRef]

24. Selymes, P. Social aspects of air transport. Period Polytech Transp. Eng. 2010, 38, 67. [CrossRef]

25. Smyth, A.; Christodoulou, G.; Dennis, N.; Al-Azzawi, M.; Campbell, J. Is air transport a necessity for social inclusion and economic development? J. Air Transp. Manag. 2012, 22, 53-59. [CrossRef]

26. Martínez Raya, A.; González-Sánchez, V.M. Efficiency and sustainability of public service obligations on scheduled air services between Almeria and Seville. Econ. Res. Ekon. Istraž. 2020,1-18. [CrossRef]

27. Poliak, M.; Križanová, A.; Semanová, Š.; Štefániková, L. The impact of procurement method of the transport services to the financial requirement of performance contracting entity. Transp. Probl. 2013, 8, 67-76.

28. Bleda, M.; Chicot, J. The role of public procurement in the formation of markets for innovation. J. Bus. Res. 2020, 107, 186-196. [CrossRef]

29. Santana, I. Do Public Service Obligations hamper the cost competitiveness of regional airlines? J. Air Transp. Manag. 2009, 15, 344-349. [CrossRef]

30. Dobruszkes, F. Does liberalisation of air transport imply increasing competition? Lessons from the European case. Transp. Policy 2009, 16, 29-39. [CrossRef]

31. Păun, I.G. Private air transport and its implications on tourism. EcoForum 2017, 6.

32. Allroggen, F.; Wittman, M.D.; Malina, R. How air transport connects the world-A new metric of air connectivity and its evolution between 1990 and 2012. Transp. Res. Part E Logist. Transp. Rev. 2015, 80, 184. [CrossRef]

33. Fageda, X.; Suárez-Alemán, A.; Serebrisky, T.; Fioravanti, R. Air connectivity in remote regions: A comprehensive review of existing transport policies worldwide. J. Air Transp. Manag. 2018, 66, 65-75. [CrossRef]

34. Veeneman, W.; Mulley, C. Multi-level governance in public transport: Governmental layering and its influence on public transport service solutions. Res. Transp. Econ. 2018, 69, 430-437. [CrossRef]

(C) 2020 by the authors. Licensee MDPI, Basel, Switzerland. This article is an open access article distributed under the terms and conditions of the Creative Commons Attribution (CC BY) license (http://creativecommons.org/licenses/by/4.0/). 